\title{
In Silico screening of some antiviral phytochemicals as drug leads against Covid-19
}

\author{
Monjur Ahmed Laskar ${ }^{1}$, Moriom Begam ${ }^{2}$ and *Manabendra Dutta Choudhury ${ }^{1}$ \\ ${ }^{1}$ Bioinformatics Centre, Assam University, Silchar - 788011, Assam, India \\ ${ }^{2}$ Department of Zoology, MHCM Science College, Algapur, Hailakandi, Assam, India \\ *Corresponding author. \\ E-mail: drmdc@bioinfoaus.ac.in; Phone: (+91)-3842 270920
}

\begin{abstract}
Background: COVID-19 caused by SARS-CoV-2 in December 2019 has become a pandemic hazard to the community health. It is a respiratory difficulty causing fever, dry cough, fatigue, shortness of breath, muscle aches and some instances lead to pneumonia. Coronaviruses have large viral RNA Genomes and are single-stranded positive-sense RNA viruses. The nsp10/nsp16 protein is an important target because it is essential for the virus to replicate, the papain-like protease (Nsp3), the main protease (Nsp5), the primary RNA-dependent RNA polymerase (Nsp12) are also attractive drug targets for this disease. The uses of phytochemicals as therapeutic agents have been increasing in recent years. Some antiviral phytochemicals were taken based on literature survey for this study.

Methods: ADME parameters and drug like nature of phytochemicals were screened using SwissADME web tool. Three dimensional structures of targets are downloaded from Protein Data Bank and docked with phytochemicals \& control by using software FlexX.

Results: Morin shows significant results in ADME screening and Drug likeness prediction studies, it shows stable bonding pattern with all four targets in compare to other phytochemicals and control, shows least score in docking and forms maximum number of hydrogen bonds with the active residues of the receptors.
\end{abstract}

Conclusion: Based on present observation of docking results, ADME parameters and drug like nature, we suggest that morin may be a potent new drug candidate against Covid-19.

Keywords: COVID-19, coronavirus, drug target, phytochemicals, Drug likeness, ADME, docking, morin

\section{Introduction}

The Severe Acute Respiratory Syndrome Coronavirus (SARS-CoV) \& the Middle East Respiratory Syndrome Coronavirus (MERS-CoV) are members of the family Coronaviridae and causes mild respiratory diseases. They affect species from animals to humans causing severe 
forms of respiratory disease. In the year 2002 SARS-CoV emerged in Guandong province of China. Its transmission caused more than 8000 cases and 774 deaths ${ }^{1}$. No specific antiviral treatment exists to conquer the disease that was earlier ended by control measures such as travel constraint and patient isolation.

In Wuhan, Hubei province of China a new form of pneumonia disease emerged in winter $2019^{2-}$ 4. It was known as SARS-CoV-2 causing the coronavirus disease 2019 (COVID-19) and rapidly spread from animals (pangolins or bats as possible sources) to humans.

COVID-19 has become a pandemic hazard to the community health. It is a respiratory difficulty causing fever, dry cough, fatigue, shortness of breath, muscle aches and some instances lead to pneumonia $^{5}$.

The transmission in humans was very fast. As on June 12, 2020, a total of 7553182 confirmed infections were reported worldwide, with 423349 deaths $^{6}$.

The World Health Organization (WHO) strategy to contain the spreading includes the decrease of human-to-human spreading by restraining the contact between individuals, thus preventing diffusion amplification events and communicating critical risk information to all communities ${ }^{6}$.

While the diagnosis of COVID-19 is based on the amplification of the viral genome in real-time PCR with specific probes, the current treatment of affected person is limited to a combination of broad-spectrum antiviral drugs ${ }^{7}$. However, in several cases this pharmacological approach has proven to be totally unproductive. Coronaviruses have large viral RNA Genomes and are singlestranded positive-sense RNA viruses ${ }^{8}$.

The nsp10/16 is a complex of two critical proteins mapped by scientists from Northwestern University, Feinberg School of Medicine, USA. This protein is also known as RNA methyltransferase or MTase. Complex nature makes it more difficult to work with. The alliance of the two pieces jointly is essential to make a functional protein. These proteins transform the genetic material of the virus to construct it and seem like the host (human) cell RNA. This permits the virus to hide from the cells, providing it time to reproduce. This is a vital target because it is essential for the virus to replicate. If a drug can be developed to inhibit nsp10/nsp16, the immune system should be able to identify the virus and eliminate it earlier ${ }^{9}$. Beside this, several other proteins having roles in viral replication, gene expression etc. like the papain-like protease (Nsp3), the main protease (Nsp5), the primary RNA-dependent RNA polymerase (Nsp12), an exoribonuclease (Nsp14), an endonuclease (Nsp15) etc. are also attractive drug targets for this disease $\mathrm{e}^{10}$.

Plants have naturally developed over the years in varied climate conditions on earth and have been bestowed with affluent composite of secondary metabolites/phytochemicals with broad 
pharmacokinetic spectrum. Around 2500 medicinal plant species have been documented worldwide $^{11,12}$ to treat a myriad of inflictions and ailments. Polyphenols, alkaloids, flavonoids, saponins, quinones, terpenes, proanthocyanidins, lignins, tannins, polysaccharides, steroids, thiosulfonates, coumarins etc. are prominent bioactive phytochemicals, which have been studied to combat viral diseases ${ }^{14-20}$ (Table 1). Therefore, the present study was conducted to discover potent anti-COVID-19 natural compounds. In this study hydroxychloroquine is taken as positive control since it is reported to be efficient in Chinese COV-19 patients ${ }^{13}$.

Table 1: Some antiviral phytochemicals

\begin{tabular}{|c|c|c|}
\hline Sl. No. & Phytochemicals & Plant (part) \\
\hline 1 & Baicalin & Scutellaria baicalensis (roots) \\
\hline 2 & Chalcones & Glycyrrhiza inflate (roots) \\
\hline 3 & Dammarenolic acid & Aglaia sp. (bark) \\
\hline 4 & Decanoylphorbol-13 acetate & Croton mauritianus (leaves) \\
\hline 5 & Excoecarianin, Loliolide & Phyllanthus urinaria (whole plant) \\
\hline 6 & Honokiol & Magnolia tree (roots, bark) \\
\hline 7 & Jubanines & Ziziphus jujuba (roots) \\
\hline 8 & Limonoids & Swietenia macrophylla (stem) \\
\hline 9 & Oleanane & Camellia japonica (flowers) \\
\hline 10 & Quercetin & Embelia ribes (seeds) \\
\hline 11 & Saikosaponins & Bupleurum kaoi (roots) \\
\hline 12 & Sennoside A & Rheum palmatum (roots) \\
\hline 13 & Silvestrol & Aglaia foveolata (leaves, bark) \\
\hline 14 & SJP-L-5 & Schisandra micrantha (roots) \\
\hline 15 & Spiroketalenol & Tanacetum vulgare (rhizome) \\
\hline 16 & Swerilactones & Swertia mileensis (whole plant) \\
\hline 17 & Xanthohumol & Humulus lupulus (whole plant) \\
\hline 18 & Oxyresveratrol & Artocarpus lakoocha \\
\hline 19 & Saikosaponin B2 & Bupleurum kaoi (Root) \\
\hline 20 & Tangeretin and nobiletin & Citrus reticulate (Pericarps) \\
\hline 21 & Jatrophane ester & $\begin{array}{c}\text { Euphorbia amygdaloides } \\
\text { spp. and semiperfoliata (Whole plant) }\end{array}$ \\
\hline 22 & Glycyrrhizic acid & Glycyrrhiza radix (Roots) \\
\hline 23 & Quercetin 3-rhamnoside & Houttuynia cordata (Aerial parts) \\
\hline
\end{tabular}




\begin{tabular}{|c|c|c|}
\hline 24 & Samarangenin B & Limonium sinense (Root) \\
\hline 25 & LPRP-Et-97543 & Liriope platyphylla (Root) \\
\hline 26 & $\begin{array}{c}\text { Tetranortriterpenoid 1-cinnamoyl- } \\
\text { 3, 11-dihydroxymeliacarpin } \\
(\mathrm{CDM})\end{array}$ & Melia azedarach L. (Leaves) \\
\hline 27 & Lignin-carbohydrate complex & Prunella vulgaris (Fruit spikes) \\
\hline 28 & Pterocarnin A & Pterocarya stenoptera (Bark) \\
\hline 29 & Chalepin and pseudane IX & Ruta angustifolia (Leaves) \\
\hline 30 & Manassantin B & Saururus chinensis (Root) \\
\hline 31 & Dicaffeoylquinic acids & Schefflera heptaphylla (Leaf stalks) \\
\hline 32 & Scopadulcic acid B & Scoparia dulcis L. (Whole plant) \\
\hline 33 & $\begin{array}{l}5,7,4 \text { ' trihydroxy-8- } \\
\text { methoxyflavone }(\mathrm{F} 36)\end{array}$ & $\begin{array}{c}\text { Scutellaria baicalensis } \\
\text { (Root) }\end{array}$ \\
\hline 34 & Naringin & grape and orange (skin) \\
\hline 35 & Myricetin & Myrica cerifera \\
\hline 36 & Inophyllum_B & Calophyllum inophyllum \\
\hline 37 & Inophyllum_P & Calophyllum inophyllum \\
\hline 38 & Pericalline & Catharanthus roseus / C. lanceus \\
\hline 39 & Chrysophanic acid & Dianella longifolia \\
\hline 40 & Nordihydroguaiaretic acid & Larrea divaricata \\
\hline 41 & Retrojusticidin B & Phyllanthus myrtifolius \\
\hline 42 & Emodin & Rheum sp. and Polygonum sp. \\
\hline 43 & Gingerol & Zingiberis rhizome \\
\hline 44 & Anthraquinone & Dianella longifolia \\
\hline 45 & Methyl rosmarinate & Hyptis atrorubens Poit \\
\hline 46 & Licoleafol & Glycyrrhiza uralensis \\
\hline 47 & Amaranthin & Amaranthus tricolor \\
\hline 48 & Calceolarioside B & Fraxinus sieboldiana \\
\hline 49 & Papaverine & Papaver somniferum \\
\hline 50 & Biopterin & Crithidia fasciculata \\
\hline 51 & Buchapine & Euodia roxburghiana \\
\hline 52 & Caribine & Hymenocallis arencola \\
\hline
\end{tabular}




\begin{tabular}{|c|c|c|}
\hline 53 & Lycorine & Clivia miniata \\
\hline 54 & Fisetin & Rhus spp. \\
\hline 55 & Morin & $\begin{array}{r}\text { Prunus dulcis, Chlorophora tinctoria, Psidium } \\
\text { guajava etc. }\end{array}$ \\
\hline 56 & Luteolin & Matricaria inodora $\mathrm{L}$. \\
\hline 57 & Rutin & Fagopyrum esculentum \\
\hline 58 & Taxifolin & Acacia catechu \\
\hline 59 & Oleanolic acid & Prosopis glandulosa \\
\hline 60 & Betulinic acid & Syzigium claviflorum \\
\hline
\end{tabular}

\section{Materials and Methods}

\section{The Ligands}

Antiviral phytochemicals were taken based on literature survey, the structure of these phytochemicals and positive control hydroxychloroquine were retrieved from PubChem Compound and by drawing using ChemOffice tools. The three dimensional structure of these compounds in sdf format were generated using OpenBabel software ${ }^{21}$.

\section{Drug likeness study and ADME Screening}

To be effective as a drug, a potent molecule must reach its target in the body in sufficient concentration, and stay there in a bioactive form long enough for the expected biologic events to occur. Drug development involves assessment of absorption, distribution, metabolism and excretion (ADME) increasingly earlier in the discovery process. SwissADME web tool was used to predict ADME parameters and drug like nature of phytochemicals ${ }^{22}$.

\section{The receptor}

The structures of drug targets: the nsp10/nsp16 protein (RNA methyltransferase or MTase), the papain-like protease $(\mathrm{Nsp} 3)$, the main protease (Nsp5), the primary RNA-dependent RNA polymerase (Nsp12) are downloaded from RCSB Protein Data Bank (http://www.rcsb.org).

\section{Active site identification}

The active sites of targets were identified by the FlexX software ${ }^{23}$.

\section{Protein - Ligand interaction using FlexX}

Docking is a term used for computational schemes that attempt to find the best matching between two molecules: a receptor and ligand ${ }^{24}$. The receptors were docked with the control and phytochemicals using software FlexX. The active site amino acids were defined in the target molecule during the target preparation. The SDF file of all the compounds was loaded in FlexX 
as docking library. The output file gave the energy values in $\mathrm{Kcal} / \mathrm{mol}$. For each docked molecule, this value was noted down.

\section{Results}

The phytochemicals selected for the study with their SMILES were noted in table 2.

Table 2: Compounds with their SMILES

\begin{tabular}{|c|c|}
\hline Compounds & SMILES \\
\hline Baicalin & $\begin{array}{l}\mathrm{C} 1=\mathrm{CC}=\mathrm{C}(\mathrm{C}=\mathrm{C} 1) \mathrm{C} 2=\mathrm{CC}(=\mathrm{O}) \mathrm{C} 3=\mathrm{C}(\mathrm{C}(=\mathrm{C}(\mathrm{C}=\mathrm{C} 3 \mathrm{O} 2) \mathrm{OC} 4 \mathrm{C}(\mathrm{C}(\mathrm{C}(\mathrm{C}(\mathrm{O} 4) \mathrm{C}(=\mathrm{O}) \mathrm{O} \\
) \mathrm{O}) \mathrm{O}) \mathrm{O}) \mathrm{O}) \mathrm{O}\end{array}$ \\
\hline $\begin{array}{l}\text { Dammarenolic } \\
\text { acid }\end{array}$ & $\begin{array}{l}\mathrm{CC}(=\mathrm{CCCC}(\mathrm{C})(\mathrm{C} 1 \mathrm{CCC} 2(\mathrm{C} 1 \mathrm{CCC} 3 \mathrm{C} 2(\mathrm{CCC}(\mathrm{C} 3(\mathrm{C}) \mathrm{CCC}(=\mathrm{O}) \mathrm{O}) \mathrm{C}(=\mathrm{C}) \mathrm{C}) \mathrm{C}) \mathrm{C}) \mathrm{O}) \\
\mathrm{C}\end{array}$ \\
\hline Excoecarianin & $\begin{array}{l}\mathrm{C} 1 \mathrm{C} 2 \mathrm{C} 3 \mathrm{C}(\mathrm{C}(\mathrm{C}(\mathrm{O} 2) \mathrm{OC}(=\mathrm{O}) \mathrm{C} 4=\mathrm{CC}(=\mathrm{C}(\mathrm{C}(=\mathrm{C} 4) \mathrm{O}) \mathrm{O}) \mathrm{O}) \mathrm{OC}(=\mathrm{O}) \mathrm{C} 5=\mathrm{CC}(=\mathrm{C}(\mathrm{C} 6 \\
=\mathrm{C} 5 \mathrm{C} 7 \mathrm{C}(=\mathrm{CC}(=\mathrm{O}) \mathrm{C}(\mathrm{C} 7(\mathrm{O}) \mathrm{O})(\mathrm{O} 6) \mathrm{O}) \mathrm{C}(=\mathrm{O}) \mathrm{O} 3) \mathrm{O}) \mathrm{O}) \mathrm{OC}(=\mathrm{O}) \mathrm{C} 8=\mathrm{C}(\mathrm{C}(=\mathrm{C}(\mathrm{C}(=\mathrm{C} \\
8) \mathrm{C} 9=\mathrm{C}(\mathrm{C}(=\mathrm{C}(\mathrm{C}=\mathrm{C} 9 \mathrm{C}(=\mathrm{O}) \mathrm{O} 1) \mathrm{OC} 1=\mathrm{C}(\mathrm{C}(=\mathrm{C}(\mathrm{C}=\mathrm{C} 1 \mathrm{C}(=\mathrm{O}) \mathrm{OC} 1 \mathrm{C} 2 \mathrm{C}(\mathrm{C}(\mathrm{COC}(=\mathrm{O} \\
) \mathrm{C} 3=\mathrm{CC}(=\mathrm{C}(\mathrm{C}(=\mathrm{C} 3 \mathrm{C} 3=\mathrm{C}(\mathrm{C}(=\mathrm{C}(\mathrm{C}=\mathrm{C} 3 \mathrm{C}(=\mathrm{O}) \mathrm{O} 2) \mathrm{O}) \mathrm{O}) \mathrm{O}) \mathrm{O}) \mathrm{O}) \mathrm{O}) \mathrm{C} 1 \mathrm{OC}(=\mathrm{O}) \mathrm{C} \\
1=\mathrm{CC}(=\mathrm{C}(\mathrm{C}(=\mathrm{C} 1) \mathrm{O}) \mathrm{O}) \mathrm{O}) \mathrm{OC}(=\mathrm{O}) \mathrm{C} 1=\mathrm{CC}(=\mathrm{C}(\mathrm{C}(=\mathrm{C} 1) \mathrm{O}) \mathrm{O}) \mathrm{O}) \mathrm{O}) \mathrm{O}) \mathrm{O}) \mathrm{O}) \mathrm{O}) \\
\mathrm{O}\end{array}$ \\
\hline Loliolide & $\mathrm{CC} 1(\mathrm{CC}(\mathrm{CC} 2(\mathrm{C} 1=\mathrm{CC}(=\mathrm{O}) \mathrm{O} 2) \mathrm{C}) \mathrm{O}) \mathrm{C}$ \\
\hline Honokiol & $\mathrm{C}=\mathrm{CCC} 1=\mathrm{CC}(=\mathrm{C}(\mathrm{C}=\mathrm{C} 1) \mathrm{O}) \mathrm{C} 2=\mathrm{CC}(=\mathrm{C}(\mathrm{C}=\mathrm{C} 2) \mathrm{O}) \mathrm{CC}=\mathrm{C}$ \\
\hline Oleanane & $\mathrm{CC} 1(\mathrm{CCC} 2(\mathrm{CCC} 3(\mathrm{C}(\mathrm{C} 2 \mathrm{C} 1) \mathrm{CCC} 4 \mathrm{C} 3(\mathrm{CCC} 5 \mathrm{C} 4(\mathrm{CCCC} 5(\mathrm{C}) \mathrm{C}) \mathrm{C}) \mathrm{C}) \mathrm{C}) \mathrm{C}) \mathrm{C}$ \\
\hline Quercetin & $\mathrm{C} 1=\mathrm{CC}(=\mathrm{C}(\mathrm{C}=\mathrm{C} 1 \mathrm{C} 2=\mathrm{C}(\mathrm{C}(=\mathrm{O}) \mathrm{C} 3=\mathrm{C}(\mathrm{C}=\mathrm{C}(\mathrm{C}=\mathrm{C} 3 \mathrm{O} 2) \mathrm{O}) \mathrm{O}) \mathrm{O}) \mathrm{O}) \mathrm{O}$ \\
\hline Sennoside A & $\begin{array}{l}\mathrm{C} 1=\mathrm{CC} 2=\mathrm{C}(\mathrm{C}(=\mathrm{C} 1) \mathrm{OC} 3 \mathrm{C}(\mathrm{C}(\mathrm{C}(\mathrm{C}(\mathrm{O} 3) \mathrm{CO}) \mathrm{O}) \mathrm{O}) \mathrm{O}) \mathrm{C}(=\mathrm{O}) \mathrm{C} 4=\mathrm{C}(\mathrm{C} 2 \mathrm{C} 5 \mathrm{C} 6=\mathrm{C}(\mathrm{C}( \\
=\mathrm{CC}=\mathrm{C} 6) \mathrm{OC} 7 \mathrm{C}(\mathrm{C}(\mathrm{C}(\mathrm{C}(\mathrm{O} 7) \mathrm{CO}) \mathrm{O}) \mathrm{O}) \mathrm{O}) \mathrm{C}(=\mathrm{O}) \mathrm{C} 8=\mathrm{C} 5 \mathrm{C}=\mathrm{C}(\mathrm{C}=\mathrm{C} 8 \mathrm{O}) \mathrm{C}(=\mathrm{O}) \mathrm{O}) \mathrm{C}= \\
\mathrm{C}(\mathrm{C}=\mathrm{C} 4 \mathrm{O}) \mathrm{C}(=\mathrm{O}) \mathrm{O}\end{array}$ \\
\hline Silvestrol & $\begin{array}{l}\mathrm{COC} 1 \mathrm{C}(\mathrm{OC}(\mathrm{CO} 1) \mathrm{C}(\mathrm{CO}) \mathrm{O}) \mathrm{OC} 2=\mathrm{CC} 3=\mathrm{C}(\mathrm{C}(=\mathrm{C} 2) \mathrm{OC}) \mathrm{C} 4(\mathrm{C}(\mathrm{C}(\mathrm{C}(\mathrm{C} 4(\mathrm{O} 3) \mathrm{C} 5=\mathrm{C} \\
\mathrm{C}=\mathrm{C}(\mathrm{C}=\mathrm{C} 5) \mathrm{OC}) \mathrm{C} 6=\mathrm{CC}=\mathrm{CC}=\mathrm{C} 6) \mathrm{C}(=\mathrm{O}) \mathrm{OC}) \mathrm{O}) \mathrm{O}\end{array}$ \\
\hline SJP-L-5 & $\mathrm{CN}(\mathrm{C}) \mathrm{C} 1=\mathrm{CC}=\mathrm{C}(\mathrm{C}=\mathrm{C} 1) \mathrm{C} 2=\mathrm{C}(\mathrm{C} 3=\mathrm{C}(\mathrm{C}=\mathrm{C} 2 \mathrm{C}(=\mathrm{O}) \mathrm{OC}) \mathrm{OCO} 3) \mathrm{OC}$ \\
\hline Xanthohumol & $\mathrm{CC}(=\mathrm{CCC} 1=\mathrm{C}(\mathrm{C}(=\mathrm{C}(\mathrm{C}=\mathrm{C} 1 \mathrm{O}) \mathrm{OC}) \mathrm{C}(=\mathrm{O}) \mathrm{C}=\mathrm{CC} 2=\mathrm{CC}=\mathrm{C}(\mathrm{C}=\mathrm{C} 2) \mathrm{O}) \mathrm{O}) \mathrm{C}$ \\
\hline Spiroketalenol & $\mathrm{CC} \# \mathrm{CC} \# \mathrm{ClC}=\mathrm{C} 1 / \mathrm{C}=\mathrm{CC} 2(\mathrm{O} 1) \mathrm{CCCCO} 2$ \\
\hline Licochalcone & $\mathrm{CC}(\mathrm{C})(\mathrm{C}=\mathrm{C}) \mathrm{C} 1=\mathrm{C}(\mathrm{C}=\mathrm{C}(\mathrm{C}(=\mathrm{C} 1) \mathrm{C}=\mathrm{CC}(=\mathrm{O}) \mathrm{C} 2=\mathrm{CC}=\mathrm{C}(\mathrm{C}=\mathrm{C} 2) \mathrm{O}) \mathrm{OC}) \mathrm{O}$ \\
\hline Chalcone & $\mathrm{C} 1=\mathrm{CC}=\mathrm{C}(\mathrm{C}=\mathrm{C} 1) \mathrm{C}=\mathrm{CC}(=\mathrm{O}) \mathrm{C} 2=\mathrm{CC}=\mathrm{CC}=\mathrm{C} 2$ \\
\hline $\begin{array}{l}\text { Decanoylphorbol- } \\
13 \text { acetate }\end{array}$ & $\begin{array}{l}\mathrm{CCCCCCCCCC}(=\mathrm{O}) \mathrm{OC} 1 \mathrm{C}(\mathrm{C} 2(\mathrm{C}(\mathrm{C}=\mathrm{C}(\mathrm{CC} 3(\mathrm{C} 2 \mathrm{C}=\mathrm{C}(\mathrm{C} 3=\mathrm{O}) \mathrm{C}) \mathrm{O}) \mathrm{CO}) \mathrm{C} 4 \mathrm{C} 1(\mathrm{C} 4 \\
(\mathrm{C}) \mathrm{C}) \mathrm{OC}(=\mathrm{O}) \mathrm{C}) \mathrm{O}) \mathrm{C}\end{array}$ \\
\hline Jubanine A & $\begin{array}{l}\mathrm{CCC}(\mathrm{C}) \mathrm{C} 1 \mathrm{C}(=\mathrm{O}) \mathrm{NC}=\mathrm{CC} 2=\mathrm{C}(\mathrm{C}=\mathrm{CC}(=\mathrm{C} 2) \mathrm{OC} 3 \mathrm{CCN}(\mathrm{C} 3 \mathrm{C}(=\mathrm{O}) \mathrm{N} 1) \mathrm{C}(=\mathrm{O}) \mathrm{C}(\mathrm{CC} \\
4=\mathrm{CC}=\mathrm{CC}=\mathrm{C} 4) \mathrm{NC}(=\mathrm{O}) \mathrm{C}(\mathrm{CC} 5=\mathrm{CC}=\mathrm{CC}=\mathrm{C} 5) \mathrm{N}(\mathrm{C}) \mathrm{C}) \mathrm{OC}\end{array}$ \\
\hline Jubanine B & $\begin{array}{l}\mathrm{CN}(\mathrm{C}) \mathrm{C}(\mathrm{CC} 1=\mathrm{CC}=\mathrm{CC}=\mathrm{C} 1) \mathrm{C}(=\mathrm{O}) \mathrm{NC}(\mathrm{CC} 2=\mathrm{CC}=\mathrm{CC}=\mathrm{C} 2) \mathrm{C}(=\mathrm{O}) \mathrm{N} 3 \mathrm{CCC} 4 \mathrm{C} 3 \mathrm{C}( \\
=\mathrm{O}) \mathrm{NC}(\mathrm{C}(=\mathrm{O}) \mathrm{NC}=\mathrm{CC} 5=\mathrm{C}(\mathrm{C}=\mathrm{CC}(=\mathrm{C} 5) \mathrm{O} 4) \mathrm{OC}) \mathrm{CC} 6=\mathrm{CC}=\mathrm{CC}=\mathrm{C} 6\end{array}$ \\
\hline $\begin{array}{l}\text { 3-Hydroxy } \\
\text { Caruilignan C }\end{array}$ & $\mathrm{COC} 1=\mathrm{CC}(=\mathrm{CC}(=\mathrm{C} 1 \mathrm{OC}) \mathrm{O}) \mathrm{C} 2 \mathrm{C} 3 \mathrm{COC}(=\mathrm{O}) \mathrm{C} 3 \mathrm{CO} 2$ \\
\hline Limonin & $\begin{array}{l}\mathrm{CC} 1(\mathrm{C} 2 \mathrm{CC}(=\mathrm{O}) \mathrm{C} 3(\mathrm{C}(\mathrm{C} 24 \mathrm{COC}(=\mathrm{O}) \mathrm{CC} 4 \mathrm{O} 1) \mathrm{CCC} 5(\mathrm{C} 36 \mathrm{C}(\mathrm{O} 6) \mathrm{C}(=\mathrm{O}) \mathrm{OC} 5 \mathrm{C} 7=\mathrm{C} \\
\mathrm{OC}=\mathrm{C} 7) \mathrm{C}) \mathrm{C}) \mathrm{C}\end{array}$ \\
\hline
\end{tabular}




\begin{tabular}{|c|c|}
\hline Oxyresveratrol & $\mathrm{C} 1=\mathrm{CC}(=\mathrm{C}(\mathrm{C}=\mathrm{C} 1 \mathrm{O}) \mathrm{O}) \mathrm{C}=\mathrm{CC} 2=\mathrm{CC}(=\mathrm{CC}(=\mathrm{C} 2) \mathrm{O}) \mathrm{O}$ \\
\hline Saikosaponin B2 & $\begin{array}{l}\mathrm{CC} 1 \mathrm{C}(\mathrm{C}(\mathrm{C}(\mathrm{C}(\mathrm{O} 1) \mathrm{OC} 2 \mathrm{CCC} 3(\mathrm{C}(\mathrm{C} 2(\mathrm{C}) \mathrm{CO}) \mathrm{CCC} 4(\mathrm{C} 3 \mathrm{C}=\mathrm{CC} 5=\mathrm{C} 6 \mathrm{CC}(\mathrm{CCC} 6(\mathrm{C}(\mathrm{C} \\
\mathrm{C} 54 \mathrm{C}) \mathrm{O}) \mathrm{CO})(\mathrm{C}) \mathrm{C}) \mathrm{C}) \mathrm{C}) \mathrm{O}) \mathrm{OC} 7 \mathrm{C}(\mathrm{C}(\mathrm{C}(\mathrm{C}(\mathrm{O} 7) \mathrm{CO}) \mathrm{O}) \mathrm{O}) \mathrm{O}) \mathrm{O}\end{array}$ \\
\hline Tangeretin & $\mathrm{COC} 1=\mathrm{CC}=\mathrm{C}(\mathrm{C}=\mathrm{C} 1) \mathrm{C} 2=\mathrm{CC}(=\mathrm{O}) \mathrm{C} 3=\mathrm{C}(\mathrm{O} 2) \mathrm{C}(=\mathrm{C}(\mathrm{C}(=\mathrm{C} 3 \mathrm{OC}) \mathrm{OC}) \mathrm{OC}) \mathrm{OC}$ \\
\hline Nobiletin & $\mathrm{COC} 1=\mathrm{C}(\mathrm{C}=\mathrm{C}(\mathrm{C}=\mathrm{C} 1) \mathrm{C} 2=\mathrm{CC}(=\mathrm{O}) \mathrm{C} 3=\mathrm{C}(\mathrm{O} 2) \mathrm{C}(=\mathrm{C}(\mathrm{C}(=\mathrm{C} 3 \mathrm{OC}) \mathrm{OC}) \mathrm{OC}) \mathrm{OC}) \mathrm{OC}$ \\
\hline Jatrophane ester & $\begin{array}{l}\mathrm{CC} 1 \mathrm{C}=\mathrm{CC}(\mathrm{C}(\mathrm{C}(\mathrm{C}(\mathrm{C}(=\mathrm{C}) \mathrm{C}(\mathrm{C} 2 \mathrm{C}(\mathrm{C} 1=\mathrm{O}) \mathrm{CC}(\mathrm{C} 2 \mathrm{C}(=\mathrm{O}) \mathrm{COC}(=\mathrm{O}) \mathrm{C} 3=\mathrm{CC}=\mathrm{CC}=\mathrm{C} 3 \\
)(\mathrm{C}) \mathrm{OC}(=\mathrm{O}) \mathrm{C}) \mathrm{OC}(=\mathrm{O}) \mathrm{C}(\mathrm{C}) \mathrm{C}) \mathrm{OC}(=\mathrm{O}) \mathrm{C} 4=\mathrm{CC}=\mathrm{CC}=\mathrm{C} 4) \mathrm{OC}(=\mathrm{O}) \mathrm{C}) \mathrm{OC}(=\mathrm{O}) \mathrm{C})(\mathrm{C} \\
) \mathrm{C}\end{array}$ \\
\hline Glycyrrhizic acid & $\begin{array}{l}\mathrm{CC} 1(\mathrm{C} 2 \mathrm{CCC} 3(\mathrm{C}(\mathrm{C} 2(\mathrm{CCC} 1 \mathrm{OC} 4 \mathrm{C}(\mathrm{C}(\mathrm{C}(\mathrm{C}(\mathrm{O} 4) \mathrm{C}(=\mathrm{O}) \mathrm{O}) \mathrm{O}) \mathrm{O}) \mathrm{OC} \mathrm{C}(\mathrm{C}(\mathrm{C}(\mathrm{C}(\mathrm{O} 5) \\
\mathrm{C}(=\mathrm{O}) \mathrm{O}) \mathrm{O}) \mathrm{O}) \mathrm{O}) \mathrm{C}) \mathrm{C}(=\mathrm{O}) \mathrm{C}=\mathrm{C} 6 \mathrm{C} 3(\mathrm{CCC} 7(\mathrm{C} 6 \mathrm{CC}(\mathrm{CC} 7)(\mathrm{C}) \mathrm{C}(=\mathrm{O}) \mathrm{O}) \mathrm{C}) \mathrm{C}) \mathrm{C}) \mathrm{C}\end{array}$ \\
\hline $\begin{array}{l}\text { Quercetin 3- } \\
\text { rhamnoside }\end{array}$ & $\begin{array}{l}\mathrm{CC} 1 \mathrm{C}(\mathrm{C}(\mathrm{C}(\mathrm{C}(\mathrm{O} 1) \mathrm{OC} 2=\mathrm{C}(\mathrm{OC} 3=\mathrm{CC}(=\mathrm{CC}(=\mathrm{C} 3 \mathrm{C} 2=\mathrm{O}) \mathrm{O}) \mathrm{O}) \mathrm{C} 4=\mathrm{CC}(=\mathrm{C}(\mathrm{C}=\mathrm{C} 4) \mathrm{O} \\
) \mathrm{O}) \mathrm{O}) \mathrm{O}) \mathrm{O}\end{array}$ \\
\hline LPRP-Et-97543 & $\mathrm{CC} 1=\mathrm{C}(\mathrm{C} 2=\mathrm{C}(\mathrm{C}=\mathrm{C} 1 \mathrm{O}) \mathrm{OCC}(\mathrm{C} 2=\mathrm{O}) \mathrm{CC} 3=\mathrm{CC}=\mathrm{C}(\mathrm{C}=\mathrm{C} 3) \mathrm{O}) \mathrm{O}$ \\
\hline Chalepin & $\mathrm{CC}(\mathrm{C})(\mathrm{C}=\mathrm{C}) \mathrm{C} 1=\mathrm{CC} 2=\mathrm{CC} 3=\mathrm{C}(\mathrm{C}=\mathrm{C} 2 \mathrm{OC} 1=\mathrm{O}) \mathrm{OC}(\mathrm{C} 3) \mathrm{C}(\mathrm{C})(\mathrm{C}) \mathrm{O}$ \\
\hline Manassantin B & $\begin{array}{l}\mathrm{CC} 1 \mathrm{C}(\mathrm{C}(\mathrm{OC} 1 \mathrm{C} 2=\mathrm{CC}(=\mathrm{C}(\mathrm{C}=\mathrm{C} 2) \mathrm{OC}(\mathrm{C}) \mathrm{C}(\mathrm{C} 3=\mathrm{CC} 4=\mathrm{C}(\mathrm{C}=\mathrm{C} 3) \mathrm{OCO} 4) \mathrm{O}) \mathrm{OC}) \mathrm{C} 5= \\
\mathrm{CC}(=\mathrm{C}(\mathrm{C}=\mathrm{C} 5) \mathrm{OC}(\mathrm{C}) \mathrm{C}(\mathrm{C} 6=\mathrm{CC}(=\mathrm{C}(\mathrm{C}=\mathrm{C} 6) \mathrm{OC}) \mathrm{OC}) \mathrm{O}) \mathrm{OC}) \mathrm{C}\end{array}$ \\
\hline $\begin{array}{l}\text { Dicaffeoylquinic } \\
\text { acid }\end{array}$ & $\begin{array}{l}\mathrm{C} 1 \mathrm{C}(\mathrm{C}(\mathrm{C}(\mathrm{CC} 1(\mathrm{C}(=\mathrm{O}) \mathrm{O}) \mathrm{O}) \mathrm{OC}(=\mathrm{O}) \mathrm{C}=\mathrm{CC} 2=\mathrm{CC}(=\mathrm{C}(\mathrm{C}=\mathrm{C} 2) \mathrm{O}) \mathrm{O}) \mathrm{OC}(=\mathrm{O}) \mathrm{C}=\mathrm{CC} \\
3=\mathrm{CC}(=\mathrm{C}(\mathrm{C}=\mathrm{C} 3) \mathrm{O}) \mathrm{O}) \mathrm{O}\end{array}$ \\
\hline $\begin{array}{l}\text { Scopadulcic acid } \\
\text { B }\end{array}$ & $\begin{array}{l}\mathrm{CC} 12 \mathrm{CCC} 3(\mathrm{C} 1) \mathrm{C}(\mathrm{CC}(\mathrm{C} 4 \mathrm{C} 3(\mathrm{CCCC} 4(\mathrm{C}) \mathrm{C}(=\mathrm{O}) \mathrm{O}) \mathrm{C}) \mathrm{OC}(=\mathrm{O}) \mathrm{C} 5=\mathrm{CC}=\mathrm{CC}=\mathrm{C} 5) \mathrm{C} \\
\mathrm{C} 2=\mathrm{O}\end{array}$ \\
\hline Naringin & $\begin{array}{l}\mathrm{CC} 1 \mathrm{C}(\mathrm{C}(\mathrm{C}(\mathrm{C}(\mathrm{O} 1) \mathrm{OC} 2 \mathrm{C}(\mathrm{C}(\mathrm{C}(\mathrm{OC} 2 \mathrm{OC} 3=\mathrm{CC}(=\mathrm{C} 4 \mathrm{C}(=\mathrm{O}) \mathrm{CC}(\mathrm{OC} 4=\mathrm{C} 3) \mathrm{C} 5=\mathrm{CC}= \\
\mathrm{C}(\mathrm{C}=\mathrm{C} 5) \mathrm{O}) \mathrm{O}) \mathrm{CO}) \mathrm{O}) \mathrm{O}) \mathrm{O}) \mathrm{O}) \mathrm{O}\end{array}$ \\
\hline Myricetin & $\mathrm{C} 1=\mathrm{C}(\mathrm{C}=\mathrm{C}(\mathrm{C}(=\mathrm{C} 1 \mathrm{O}) \mathrm{O}) \mathrm{O}) \mathrm{C} 2=\mathrm{C}(\mathrm{C}(=\mathrm{O}) \mathrm{C} 3=\mathrm{C}(\mathrm{C}=\mathrm{C}(\mathrm{C}=\mathrm{C} 3 \mathrm{O} 2) \mathrm{O}) \mathrm{O}) \mathrm{O}$ \\
\hline Inophyllum_B & $\begin{array}{l}\mathrm{CC} 1 \mathrm{C}(\mathrm{OC} 2=\mathrm{C}(\mathrm{C} 1 \mathrm{O}) \mathrm{C} 3=\mathrm{C}(\mathrm{C}(=\mathrm{CC}(=\mathrm{O}) \mathrm{O} 3) \mathrm{C} 4=\mathrm{CC}=\mathrm{CC}=\mathrm{C} 4) \mathrm{C} 5=\mathrm{C} 2 \mathrm{C}=\mathrm{CC}(\mathrm{O} 5)( \\
\mathrm{C}) \mathrm{C}) \mathrm{C}\end{array}$ \\
\hline Inophyllum_P & $\begin{array}{l}\mathrm{CC} 1 \mathrm{C}(\mathrm{OC} 2=\mathrm{C}(\mathrm{C} 1 \mathrm{O}) \mathrm{C} 3=\mathrm{C}(\mathrm{C}(=\mathrm{CC}(=\mathrm{O}) \mathrm{O} 3) \mathrm{C} 4=\mathrm{CC}=\mathrm{CC}=\mathrm{C} 4) \mathrm{C} 5=\mathrm{C} 2 \mathrm{C}=\mathrm{CC}(\mathrm{O} 5)( \\
\mathrm{C}) \mathrm{C}) \mathrm{C}\end{array}$ \\
\hline Pericalline & $\mathrm{CC}=\mathrm{C} 1 \mathrm{CN} 2 \mathrm{CCC} 1 \mathrm{C}(=\mathrm{C}) \mathrm{C} 3=\mathrm{C}(\mathrm{C} 2) \mathrm{C}=\mathrm{C} 4 \mathrm{C}=\mathrm{CNC} 4=\mathrm{C} 3$ \\
\hline $\begin{array}{l}\text { Chrysophanic } \\
\text { acid }\end{array}$ & $\mathrm{CC} 1=\mathrm{CC} 2=\mathrm{C}(\mathrm{C}(=\mathrm{C} 1) \mathrm{O}) \mathrm{C}(=\mathrm{O}) \mathrm{C} 3=\mathrm{C}(\mathrm{C} 2=\mathrm{O}) \mathrm{C}=\mathrm{CC}=\mathrm{C} 3 \mathrm{O}$ \\
\hline $\begin{array}{l}\text { Nordihydroguaiar } \\
\text { etic acid }\end{array}$ & $\mathrm{CC}(\mathrm{CC} 1=\mathrm{CC}(=\mathrm{C}(\mathrm{C}=\mathrm{C} 1) \mathrm{O}) \mathrm{O}) \mathrm{C}(\mathrm{C}) \mathrm{CC} 2=\mathrm{CC}(=\mathrm{C}(\mathrm{C}=\mathrm{C} 2) \mathrm{O}) \mathrm{O}$ \\
\hline Retrojusticidin B & $\mathrm{COC} 1=\mathrm{CC} 2=\mathrm{CC} 3=\mathrm{C}(\mathrm{COC} 3=\mathrm{O}) \mathrm{C}(=\mathrm{C} 2 \mathrm{C}=\mathrm{C} 1 \mathrm{OC}) \mathrm{C} 4=\mathrm{CC} 5=\mathrm{C}(\mathrm{C}=\mathrm{C} 4) \mathrm{OCO} 5$ \\
\hline Emodin & $\mathrm{CC} 1=\mathrm{CC} 2=\mathrm{C}(\mathrm{C}(=\mathrm{C} 1) \mathrm{O}) \mathrm{C}(=\mathrm{O}) \mathrm{C} 3=\mathrm{C}(\mathrm{C} 2=\mathrm{O}) \mathrm{C}=\mathrm{C}(\mathrm{C}=\mathrm{C} 3 \mathrm{O}) \mathrm{O}$ \\
\hline Gingerol & $\operatorname{CCCCCC}(\mathrm{CC}(=\mathrm{O}) \mathrm{CCC} 1=\mathrm{CC}(=\mathrm{C}(\mathrm{C}=\mathrm{C} 1) \mathrm{O}) \mathrm{OC}) \mathrm{O}$ \\
\hline Anthraquinone & $\mathrm{C} 1=\mathrm{CC}=\mathrm{C} 2 \mathrm{C}(=\mathrm{C} 1) \mathrm{C}(=\mathrm{O}) \mathrm{C} 3=\mathrm{CC}=\mathrm{CC}=\mathrm{C} 3 \mathrm{C} 2=\mathrm{O}$ \\
\hline $\begin{array}{c}\text { Methyl } \\
\text { rosmarinate }\end{array}$ & $\mathrm{COC}(=\mathrm{O}) \mathrm{C}(\mathrm{CC} 1=\mathrm{CC}(=\mathrm{C}(\mathrm{C}=\mathrm{C} 1) \mathrm{O}) \mathrm{O}) \mathrm{OC}(=\mathrm{O}) \mathrm{C}=\mathrm{CC} 2=\mathrm{CC}(=\mathrm{C}(\mathrm{C}=\mathrm{C} 2) \mathrm{O}) \mathrm{O}$ \\
\hline Licoleafol & $\mathrm{CC}(=\mathrm{CCC} 1=\mathrm{C} 2 \mathrm{C}(=\mathrm{C}(\mathrm{C}=\mathrm{C} 1 \mathrm{O}) \mathrm{O}) \mathrm{C}(=\mathrm{O}) \mathrm{CC}(\mathrm{O} 2) \mathrm{C} 3=\mathrm{CC}(=\mathrm{C}(\mathrm{C}=\mathrm{C} 3) \mathrm{O}) \mathrm{O}) \mathrm{CO}$ \\
\hline Amaranthin & $\begin{array}{l}\mathrm{C} 1 \mathrm{C}(\mathrm{NC}(=\mathrm{CC} 1=\mathrm{CC}=[\mathrm{N}+] 2 \mathrm{C}(\mathrm{CC} 3=\mathrm{CC}(=\mathrm{C}(\mathrm{C}=\mathrm{C} 32) \mathrm{O}) \mathrm{OC} 4 \mathrm{C}(\mathrm{C}(\mathrm{C}(\mathrm{C}(\mathrm{O} 4) \mathrm{CO}) \mathrm{O}) \\
\mathrm{O}) \mathrm{OC} 5 \mathrm{C}(\mathrm{C}(\mathrm{C}(\mathrm{C}(\mathrm{O} 5) \mathrm{C}(=\mathrm{O}) \mathrm{O}) \mathrm{O}) \mathrm{O}) \mathrm{O}) \mathrm{C}(=\mathrm{O})[\mathrm{O}-]) \mathrm{C}(=\mathrm{O}) \mathrm{O}) \mathrm{C}(=\mathrm{O}) \mathrm{O}\end{array}$ \\
\hline Calceolarioside B & $\begin{array}{l}\mathrm{C} 1=\mathrm{CC}(=\mathrm{C}(\mathrm{C}=\mathrm{C} 1 \mathrm{CCOC} 2 \mathrm{C}(\mathrm{C}(\mathrm{C}(\mathrm{C}(\mathrm{O} 2) \mathrm{COC}(=\mathrm{O}) \mathrm{C}=\mathrm{CC} 3=\mathrm{CC}(=\mathrm{C}(\mathrm{C}=\mathrm{C} 3) \mathrm{O}) \mathrm{O}) \\
\mathrm{O}) \mathrm{O}) \mathrm{O}) \mathrm{O}) \mathrm{O}\end{array}$ \\
\hline
\end{tabular}




\begin{tabular}{|c|c|}
\hline Papaverine & $\mathrm{COC} 1=\mathrm{C}(\mathrm{C}=\mathrm{C}(\mathrm{C}=\mathrm{C} 1) \mathrm{CC} 2=\mathrm{NC}=\mathrm{CC} 3=\mathrm{CC}(=\mathrm{C}(\mathrm{C}=\mathrm{C} 32) \mathrm{OC}) \mathrm{OC}) \mathrm{OC}$ \\
\hline Biopterin & $\mathrm{CC}(\mathrm{C}(\mathrm{C} 1=\mathrm{CN}=\mathrm{C} 2 \mathrm{C}(=\mathrm{N} 1) \mathrm{C}(=\mathrm{O}) \mathrm{NC}(=\mathrm{N} 2) \mathrm{N}) \mathrm{O}) \mathrm{O}$ \\
\hline Buchapine & $\mathrm{CC}(=\mathrm{CCC} 1(\mathrm{C}(=\mathrm{O}) \mathrm{C} 2=\mathrm{CC}=\mathrm{CC}=\mathrm{C} 2 \mathrm{NC} 1=\mathrm{O}) \mathrm{C}(\mathrm{C})(\mathrm{C}) \mathrm{C}=\mathrm{C}) \mathrm{C}$ \\
\hline Caribine & $\mathrm{C} 1 \mathrm{CC} 2 \mathrm{C}=\mathrm{C} 3 \mathrm{C}(\mathrm{CN} 4 \mathrm{C} 3 \mathrm{C}(\mathrm{C} 2 \mathrm{NC} 1) \mathrm{C} 5=\mathrm{CC} 6=\mathrm{C}(\mathrm{C}=\mathrm{C} 5 \mathrm{C} 4) \mathrm{OCO} 6) \mathrm{O}$ \\
\hline Lycorine & $\mathrm{C} 1 \mathrm{CN} 2 \mathrm{CC} 3=\mathrm{CC} 4=\mathrm{C}(\mathrm{C}=\mathrm{C} 3 \mathrm{C} 5 \mathrm{C} 2 \mathrm{C} 1=\mathrm{CC}(\mathrm{C} 5 \mathrm{O}) \mathrm{O}) \mathrm{OCO} 4$ \\
\hline Fisetin & $\mathrm{C} 1=\mathrm{CC}(=\mathrm{C}(\mathrm{C}=\mathrm{C} 1 \mathrm{C} 2=\mathrm{C}(\mathrm{C}(=\mathrm{O}) \mathrm{C} 3=\mathrm{C}(\mathrm{O} 2) \mathrm{C}=\mathrm{C}(\mathrm{C}=\mathrm{C} 3) \mathrm{O}) \mathrm{O}) \mathrm{O}) \mathrm{O}$ \\
\hline Morin & $\mathrm{C} 1=\mathrm{CC}(=\mathrm{C}(\mathrm{C}=\mathrm{C} 1 \mathrm{O}) \mathrm{O}) \mathrm{C} 2=\mathrm{C}(\mathrm{C}(=\mathrm{O}) \mathrm{C} 3=\mathrm{C}(\mathrm{C}=\mathrm{C}(\mathrm{C}=\mathrm{C} 3 \mathrm{O} 2) \mathrm{O}) \mathrm{O}) \mathrm{O}$ \\
\hline Luteolin & $\mathrm{C} 1=\mathrm{CC}(=\mathrm{C}(\mathrm{C}=\mathrm{C} 1 \mathrm{C} 2=\mathrm{CC}(=\mathrm{O}) \mathrm{C} 3=\mathrm{C}(\mathrm{C}=\mathrm{C}(\mathrm{C}=\mathrm{C} 3 \mathrm{O} 2) \mathrm{O}) \mathrm{O}) \mathrm{O}) \mathrm{O}$ \\
\hline Rutin & $\begin{array}{l}\mathrm{CC} 1 \mathrm{C}(\mathrm{C}(\mathrm{C}(\mathrm{C}(\mathrm{O} 1) \mathrm{OCC} 2 \mathrm{C}(\mathrm{C}(\mathrm{C}(\mathrm{C}(\mathrm{O} 2) \mathrm{OC} 3=\mathrm{C}(\mathrm{OC} 4=\mathrm{CC}(=\mathrm{CC}(=\mathrm{C} 4 \mathrm{C} 3=\mathrm{O}) \mathrm{O}) \mathrm{O}) \\
\mathrm{C} 5=\mathrm{CC}(=\mathrm{C}(\mathrm{C}=\mathrm{C} 5) \mathrm{O}) \mathrm{O}) \mathrm{O}) \mathrm{O}) \mathrm{O}) \mathrm{O}) \mathrm{O}) \mathrm{O}\end{array}$ \\
\hline Taxifolin & $\mathrm{C} 1=\mathrm{CC}(=\mathrm{C}(\mathrm{C}=\mathrm{C} 1 \mathrm{C} 2 \mathrm{C}(\mathrm{C}(=\mathrm{O}) \mathrm{C} 3=\mathrm{C}(\mathrm{C}=\mathrm{C}(\mathrm{C}=\mathrm{C} 3 \mathrm{O} 2) \mathrm{O}) \mathrm{O}) \mathrm{O}) \mathrm{O}) \mathrm{O}$ \\
\hline Oleanolic acid & $\begin{array}{l}\mathrm{CC} 1(\mathrm{CCC} 2(\mathrm{CCC} 3(\mathrm{C}(=\mathrm{CCC} 4 \mathrm{C} 3(\mathrm{CCC} 5 \mathrm{C} 4(\mathrm{CCC}(\mathrm{C} 5(\mathrm{C}) \mathrm{C}) \mathrm{O}) \mathrm{C}) \mathrm{C}) \mathrm{C} 2 \mathrm{C} 1) \mathrm{C}) \mathrm{C}(=\mathrm{O} \\
) \mathrm{O}) \mathrm{C}\end{array}$ \\
\hline Betulinic acid & $\begin{array}{l}\mathrm{CC}(=\mathrm{C}) \mathrm{C} 1 \mathrm{CCC} 2(\mathrm{C} 1 \mathrm{C} 3 \mathrm{CCC} 4 \mathrm{C} 5(\mathrm{CCC}(\mathrm{C}(\mathrm{C} 5 \mathrm{CCC} 4(\mathrm{C} 3(\mathrm{CC} 2) \mathrm{C}) \mathrm{C})(\mathrm{C}) \mathrm{C}) \mathrm{O}) \mathrm{C}) \mathrm{C}( \\
=\mathrm{O}) \mathrm{O}\end{array}$ \\
\hline $\begin{array}{l}\text { Hydroxychloroqu } \\
\text { ine }\end{array}$ & $\mathrm{CCN}(\mathrm{CCCC}(\mathrm{C}) \mathrm{NC} 1=\mathrm{C} 2 \mathrm{C}=\mathrm{CC}(=\mathrm{CC} 2=\mathrm{NC}=\mathrm{C} 1) \mathrm{Cl}) \mathrm{CCO}$ \\
\hline
\end{tabular}

For any molecule to become a drug it should not have any toxic or allergenic effects and it should possess all the ADME properties. ADME screening and Drug likeness properties of some phytochemicals were shown below

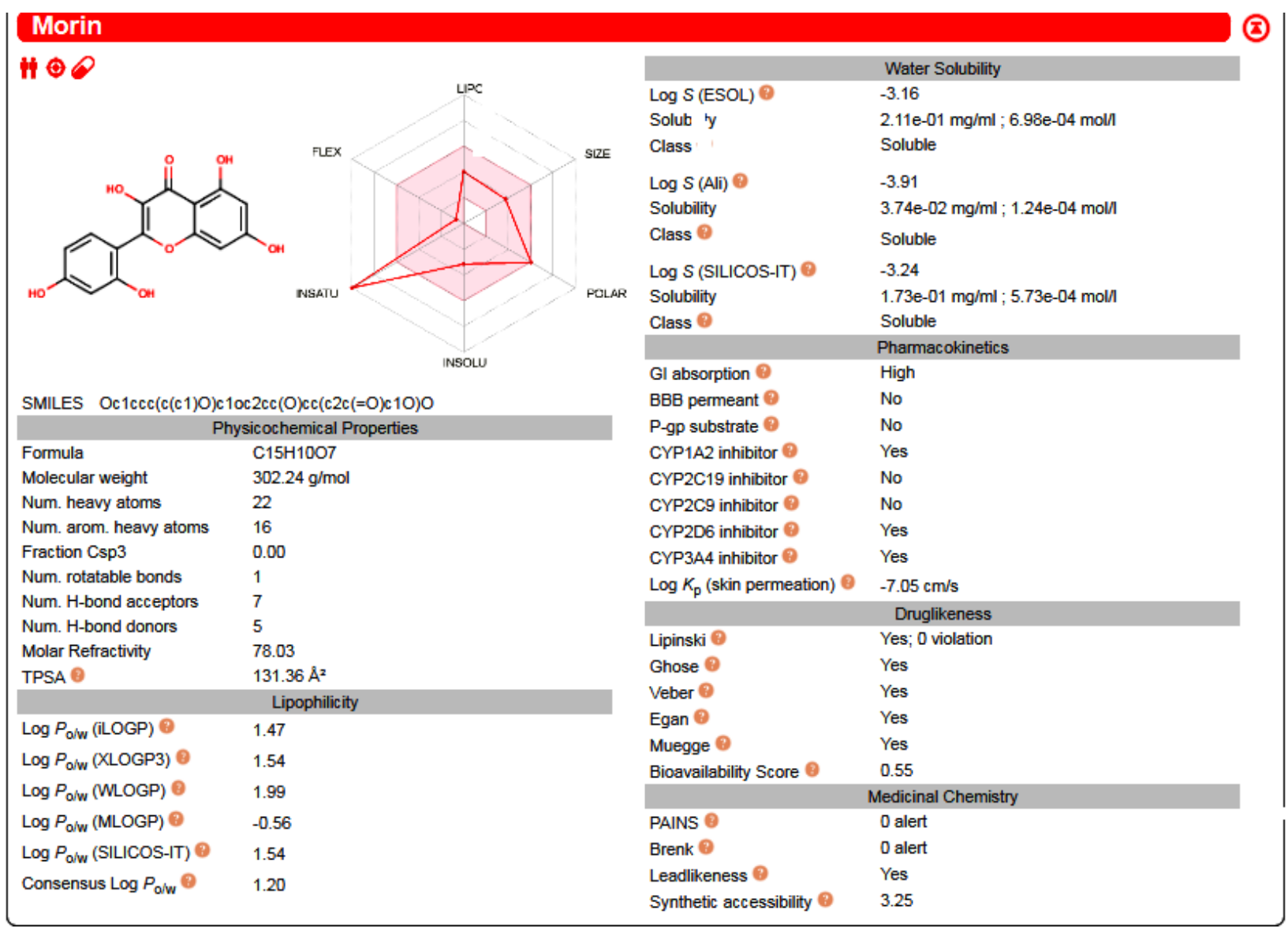




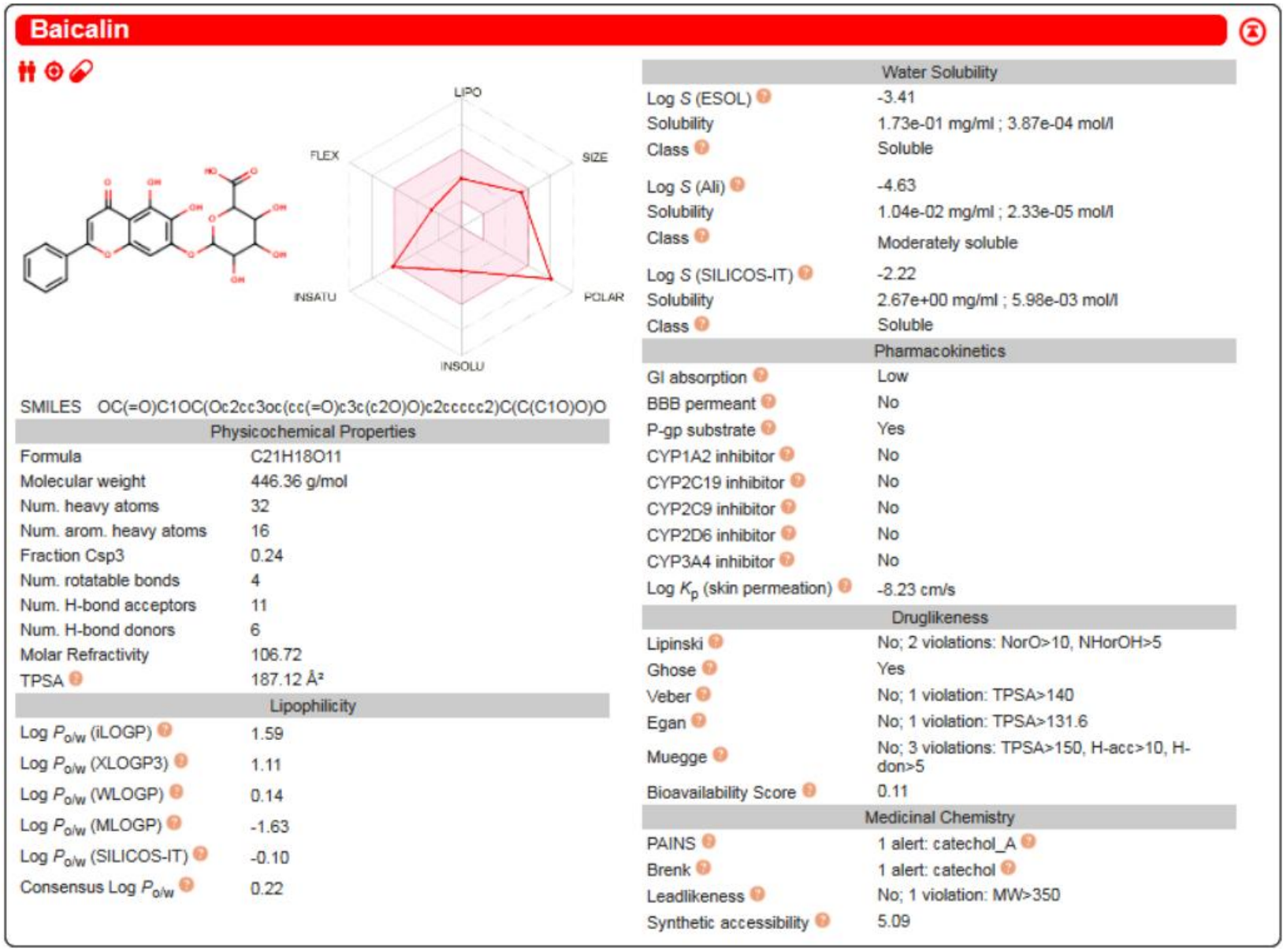

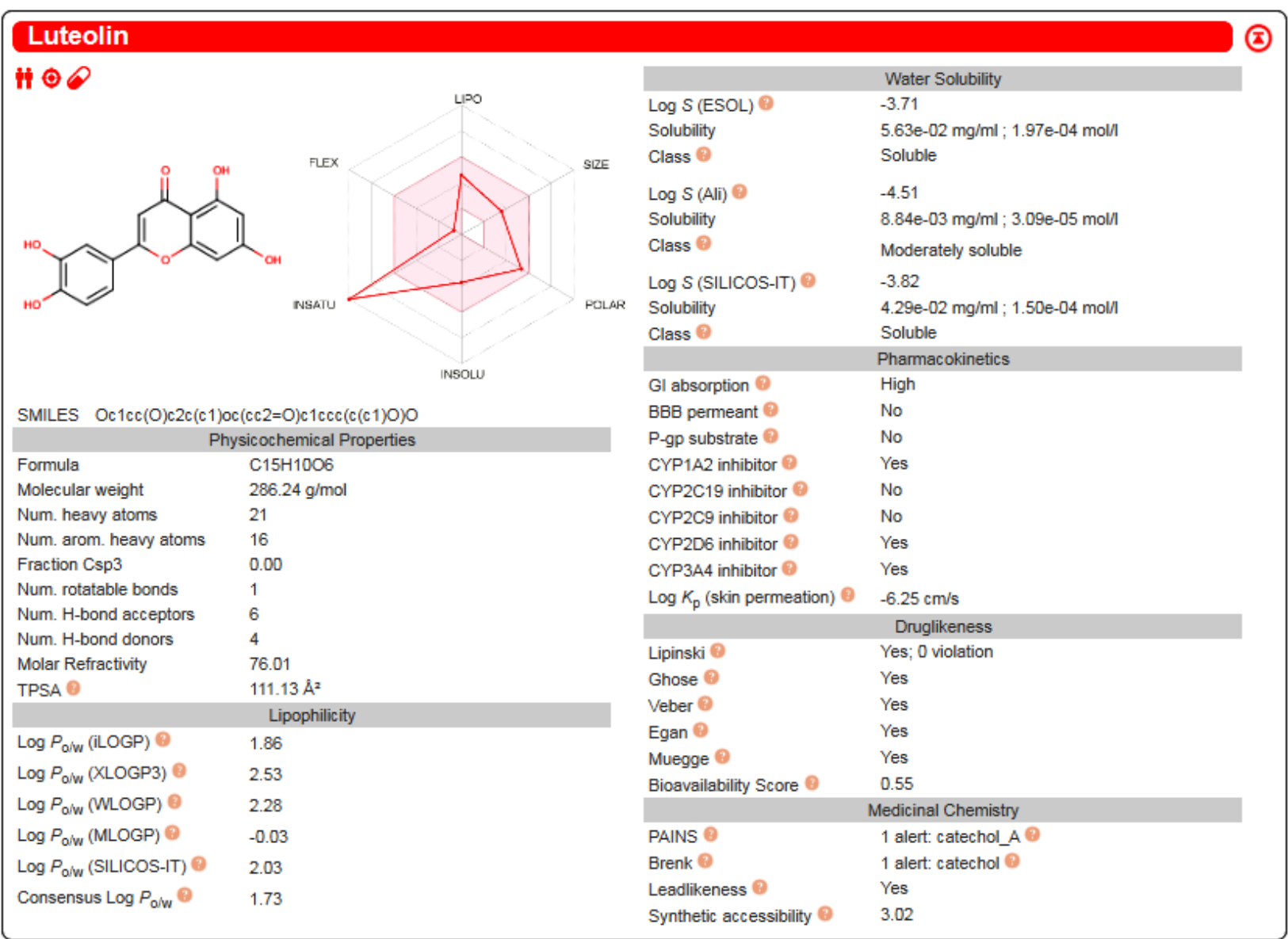




\section{$H \circ 0$}<smiles>O=C1c2cc(I)cc(O)c2C(=O)c2cc(O)cc(O)c21</smiles>
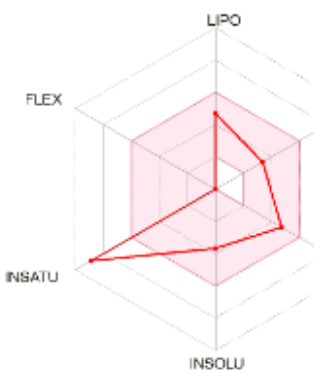

SMILES $\mathrm{Cc} 1 \mathrm{cc}(\mathrm{O}) \mathrm{c} 2 \mathrm{c}(\mathrm{c} 1) \mathrm{C}(=0) \mathrm{c} 1 \mathrm{c}(\mathrm{C} 2=0) \mathrm{c}(\mathrm{O}) \mathrm{cc}(\mathrm{c} 1) \mathrm{O}$

\section{Physicochemical Properties
PMLS}

Formula $\quad \mathrm{C} 15 \mathrm{H} 1005$

Molecular weight $\quad 270.24 \mathrm{~g} / \mathrm{mol}$

Num. heavy atoms 20

Num. arom. heavy atoms 12

Fraction Csp3 $\quad 0.07$

Num. rotatable bonds $\quad 0$

Num. H-bond acceptors 5

Num. H-bond donors 3

Molar Refractivity $\quad 70.78$

$\log P_{\text {oiv }}$ (iLOGP) 91.81

$\log P_{\text {oiw }}$ (XLOGP3) $\quad 2.72$

$\log P_{\text {o/w }}$ (WLOGP) 01.89

$\log P_{\text {oiv }}$ (MLOGP) 0.36

$\log P_{\text {o/w }}$ (SILICOS-IT) 2.55

Consensus Log $P_{\text {o/w }}$ ? 1.87
TPSA $0 \quad 94.83 \AA^{2}$

Water Solubility

$-3.67$

$5.74 \mathrm{e}-02 \mathrm{mg} / \mathrm{ml} ; 2.12 \mathrm{e}-04 \mathrm{~mol} / 1$

Soluble

SIZE

Class 2

$-4.37$

$1.17 \mathrm{e}-02 \mathrm{mg} / \mathrm{ml} ; 4.31 \mathrm{e}-05 \mathrm{~mol} / \mathrm{l}$

$\begin{array}{ll}\text { Solubility } & 1.17 \mathrm{e}-02 \mathrm{mg} / \mathrm{ml} ; 4 \\ \text { Class }(2) & \text { Moderately soluble }\end{array}$

Log S (SILICOS-IT) 20

POLAR Solubility $\quad 3.36 \mathrm{e}-02 \mathrm{mg} / \mathrm{ml} ; 1.24 \mathrm{e}-04 \mathrm{~mol} / \mathrm{l}$

Class (2) Soluble

GI absorption 2 Pharmacokinetics

Gl absorption 3 High

BBB permeant 2 No

P-gp substrate $2 \quad$ No

CYP1A2 inhibitor $2 \quad$ Yes

CYP2C19 inhibitor 2 No

CYP2C9 inhibitor $2 \quad$ No

CYP2D6 inhibitor 2 No

CYP3A4 inhibitor 2 Yes

Log $K_{\mathrm{p}}$ (skin permeation) $0 \quad-6.02 \mathrm{~cm} / \mathrm{s}$

\begin{tabular}{|c|c|}
\hline \multicolumn{2}{|r|}{ Druglikeness } \\
\hline Lipinski 2 & Yes; 0 violation \\
\hline Ghose 2 & Yes \\
\hline Veber 2 & Yes \\
\hline Egan 2 & Yes \\
\hline Muegge 2 & Yes \\
\hline Bioavailability Score ${ }^{8}$ & 0.55 \\
\hline \multicolumn{2}{|r|}{ Medicinal Chemistry } \\
\hline PAINS 9 & 1 alert: quinone_A $(3)$ \\
\hline Brenk 2 & 0 alert \\
\hline Leadlikeness $(2)$ & Yes \\
\hline Synthetic accessibility $(2$ & 2.57 \\
\hline
\end{tabular}

Hydroxychloroquine

$H \odot 0$<smiles>CCCN(CO)CCCC(Cl)Nc1ccnc2cc(Cl)ccc12</smiles>

\section{FLEX}

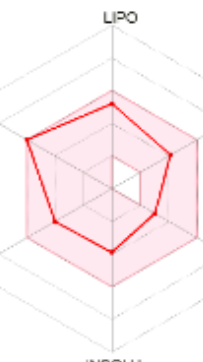

INSOL

SMILES OCCN $(\mathrm{CCCC}(\mathrm{Nc} 1 \mathrm{ccnc} 2 \mathrm{c} 1 \mathrm{ccc}(\mathrm{c} 2) \mathrm{Cl}) \mathrm{C}) \mathrm{CC}$

Physicochemical Properties

Formula $\quad$ C18H26CIN3O

Molecular weight $\quad 335.87 \mathrm{~g} / \mathrm{mol}$

Num. heavy atoms $\quad 23$

Num. arom. heavy atoms 10

Fraction Csp3 $\quad 0.50$

Num. rotatable bonds $\quad 9$

Num. H-bond acceptors 3

Num. H-bond donors 2

Molar Refractivity $\quad 98.57$

TPSA $0 \quad 48.39 \AA^{2}$

$\log P_{\text {oiw }}$ (iLOGP) 3.58

$\log P_{\text {oiw }}(X L O G P 3) \Theta 3.58$

$\log P_{\text {oiv }}$ (WLOGP) 03.59

$\log P_{\text {o/w }}$ (MLOGP) 202.35

$\log P_{\text {oiv }}$ (SILICOS-IT) 23.73

Consensus Log $P_{\text {o/w }}$ (2) $\quad 3.37$
Water Solubility

$-3.91$

$4.17 \mathrm{e}-02 \mathrm{mg} / \mathrm{ml} ; 1.24 \mathrm{e}-04 \mathrm{~mol} / \mathrm{l}$

Soluble

SIZE

$-4.28$

$1.75 \mathrm{e}-02 \mathrm{mg} / \mathrm{ml} ; 5.22 \mathrm{e}-05 \mathrm{~mol} / 1$

Moderately soluble

Class 1

Log S (SILICOS-IT) 2

POLAR

Solubility

Class 2

$1.50 \mathrm{e}-04 \mathrm{mg} / \mathrm{ml} ; 4.46 \mathrm{e}-07 \mathrm{~mol} / \mathrm{l}$

Poorly soluble

Pharmacokinetics

Gl absorption 2 High

BBB permeant $(2) \quad Y e s$

P-gp substrate $P$ No

CYP1A2 inhibitor 2 Yes

CYP2C19 inhibitor 2 No

CYP2C9 inhibitor 2 No

CYP2D6 inhibitor 2 Yes

CYP3A4 inhibitor (2) No

$\log K_{\mathrm{p}}$ (skin permeation) $-\quad-5.81 \mathrm{~cm} / \mathrm{s}$

\begin{tabular}{|c|c|}
\hline \multicolumn{2}{|r|}{ Druglikeness } \\
\hline Lipinski 2 & Yes; 0 violation \\
\hline Ghose 8 & Yes \\
\hline Veber 2 & Yes \\
\hline Egan 2 & Yes \\
\hline Muegge 0 & Yes \\
\hline Bioavailability Score & 0.55 \\
\hline \multicolumn{2}{|r|}{ Medicinal Chemistry } \\
\hline PAINS 8 & 0 alert \\
\hline Brenk 2 & 0 alert \\
\hline Leadlikeness $(2)$ & No; 2 violations: Rotors $>7$, XLOGP $3>3.5$ \\
\hline Synthetic accessibility 2 & 2.82 \\
\hline
\end{tabular}

ADME and drug likeness screening results of some phytochemicals and control 
Three dimensional structures of targets are downloaded from Protein Data Bank having PDB ids: 6W75, 6W9C, 6LU7 and 6M71 for the nsp10/nsp16 protein (RNA methyltransferase or MTase), the papain-like protease (Nsp3), the main protease (Nsp5) and RNA-dependent RNA polymerase (Nsp12) respectively.

Interaction energies between ligand and receptor play the most crucial role in drug designing. In this work, drug targets the nsp10/nsp16 protein (RNA methyltransferase or MTase), the papainlike protease (Nsp3), the main protease (Nsp5) and RNA-dependent RNA polymerase (Nsp12) and the interactions of the compounds were studied using FlexX. The docking results of compounds with targets are described in table 3. The docking poses are shown in Figures (Figure 1 - Figure 5).

Table 3: Docking results of targets with phytochemicals and control

\begin{tabular}{|c|c|c|c|c|}
\hline \multirow[t]{2}{*}{ Phytochemicals } & \multicolumn{4}{|c|}{ Docking Score (Kcal/mol) } \\
\hline & $\begin{array}{c}\text { NSP10 - NSP16 } \\
\text { Complex }\end{array}$ & $\begin{array}{c}\text { Papain-like } \\
\text { protease }\end{array}$ & $\begin{array}{l}\text { RNA-dependent } \\
\text { RNA polymerase }\end{array}$ & $\begin{array}{c}\text { COVID-19 } \\
\text { main } \\
\text { protease }\end{array}$ \\
\hline Baicalin & -19.7773 & -34.3309 & -19.3806 & -12.1868 \\
\hline Dammarenolic acid & -7.2746 & -8.3572 & -2.6079 & 2.5649 \\
\hline Excoecarianin & 0.0000 & 0.0000 & 0.0000 & 0.0000 \\
\hline Loliolide & -12.3698 & -14.5091 & -11.4858 & -8.0941 \\
\hline Honokiol & -15.9008 & -13.9542 & -15.7179 & -8.6464 \\
\hline Oleanane & 0.0000 & 0.0000 & 0.0000 & 0.0000 \\
\hline Quercetin & -24.5804 & -24.9869 & -20.6509 & -12.0769 \\
\hline Sennoside A & -11.2257 & -21.5574 & -13.4283 & 2.0780 \\
\hline Silvestrol & -6.4271 & -14.5208 & -7.9343 & 4.6139 \\
\hline SJP-L-5 & -16.4261 & -16.8003 & -12.8650 & -5.8154 \\
\hline Xanthohumol & -16.9845 & -24.9632 & -16.9412 & -8.4929 \\
\hline Spiroketalenol & -14.9469 & -12.8823 & -14.8976 & -5.3747 \\
\hline Licochalcone & -14.6707 & -19.1733 & -13.2370 & -7.4708 \\
\hline Chalcone & -14.8018 & -17.7265 & -14.4728 & -8.5971 \\
\hline $\begin{array}{c}\text { Decanoylphorbol-13 } \\
\text { acetate }\end{array}$ & -2.5114 & -4.3715 & -1.0579 & 6.5114 \\
\hline Jubanine A & -16.7469 & -28.0104 & -9.8798 & -2.0363 \\
\hline
\end{tabular}




\begin{tabular}{|c|c|c|c|c|}
\hline Jubanine B & 0.0000 & 0.0000 & 0.0000 & 0.0000 \\
\hline 3-Hydroxy Caruilignan $\mathrm{C}$ & -14.8918 & -17.8282 & -14.5065 & -5.4153 \\
\hline Limonin & 0.0000 & 0.0000 & 0.0000 & 0.0000 \\
\hline Oxyresveratrol & -23.2724 & -21.5388 & -18.6387 & -15.3810 \\
\hline Saikosaponin B2 & 0.0000 & 0.0000 & 0.0000 & 0.0000 \\
\hline Tangeretin & -13.5612 & -12.9554 & -9.9507 & -1.3688 \\
\hline Nobiletin & -17.2219 & -13.2152 & -9.4153 & -2.7587 \\
\hline Jatrophane ester & 0.0000 & 0.0000 & 0.0000 & 0.0000 \\
\hline Glycyrrhizic acid & 0.0000 & 0.0000 & 0.0000 & 0.0000 \\
\hline Quercetin 3-rhamnoside & -24.6582 & -27.3896 & -21.2587 & -13.0196 \\
\hline LPRP-Et-97543 & -20.5395 & -23.0514 & -19.8869 & -14.6944 \\
\hline Chalepin & -15.0850 & -15.5800 & -11.4380 & -4.4533 \\
\hline Manassantin B & -12.4506 & -24.5615 & -8.2997 & 10.8517 \\
\hline Dicaffeoylquinic acid & -21.7308 & -24.2442 & -17.0935 & -3.3438 \\
\hline Scopadulcic acid B & 0.0000 & 0.0000 & 0.0000 & 0.0000 \\
\hline Naringin & -14.5846 & -25.7657 & -13.6635 & -3.7149 \\
\hline Myricetin & -24.5445 & -24.8053 & -20.7303 & -11.4399 \\
\hline Inophyllum_B & -14.3457 & -18.4011 & -16.6309 & -6.3468 \\
\hline Inophyllum_P & -14.3457 & -18.4011 & -16.6309 & -6.3468 \\
\hline Pericalline & -16.3447 & -20.8096 & -11.5925 & -11.7141 \\
\hline Chrysophanic acid & -20.8292 & -22.4865 & -20.0624 & -14.3095 \\
\hline Nordihydroguaiaretic acid & -18.3887 & -21.6118 & -14.2268 & -11.5398 \\
\hline Retrojusticidin B & -12.8700 & -23.3895 & -16.3522 & -7.3189 \\
\hline Emodin & -21.4040 & -23.1325 & -21.6234 & -20.0202 \\
\hline Gingerol & -13.9236 & -13.5592 & -9.9803 & -1.4682 \\
\hline Anthraquinone & -12.1782 & -15.7292 & -13.9016 & -8.0614 \\
\hline Methyl rosmarinate & -23.5380 & -26.3787 & -16.0964 & -5.6176 \\
\hline Licoleafol & -16.5607 & -26.5293 & -15.9209 & -11.1106 \\
\hline Amaranthin & -16.7487 & -29.2696 & -18.8189 & -10.5730 \\
\hline Calceolarioside B & -21.5665 & -33.3063 & -14.0840 & -8.3660 \\
\hline Papaverine & -10.5395 & -13.0222 & -11.9049 & -4.6477 \\
\hline Biopterin & -22.4536 & -26.9995 & -22.0282 & -15.6592 \\
\hline
\end{tabular}




\begin{tabular}{|c|c|c|c|c|}
\hline Buchapine & -11.2879 & -15.4712 & -10.8268 & -5.6774 \\
\hline Caribine & -21.4095 & -20.7228 & -16.7849 & -15.5639 \\
\hline Lycorine & -19.0653 & -28.8497 & -17.4176 & -10.3894 \\
\hline Fisetin & -23.8578 & -24.2011 & -21.7482 & -13.5647 \\
\hline Morin & $\mathbf{- 2 6 . 8 2 5 5}$ & -24.9316 & -23.6366 & -12.7982 \\
\hline Luteolin & -24.5968 & -25.9438 & $\mathbf{- 2 4 . 3 6 3 5}$ & -10.9155 \\
\hline Rutin & -15.5553 & -27.0507 & -17.3833 & -9.4748 \\
\hline Taxifolin & -24.8729 & -25.5836 & -21.3850 & -15.6423 \\
\hline Oleanolic acid & 0.0000 & 0.0000 & 0.0000 & 0.0000 \\
\hline Betulinic acid & $\mathbf{- 8 . 7 6 0 1}$ & -10.5598 & -6.1947 & -1.7703 \\
\hline Hydroxychloroquine & $\mathbf{- 1 6 . 8 4 3 3}$ & $\mathbf{- 1 7 . 4 2 2 3}$ & $\mathbf{- 1 5 . 7 8 6 4}$ & $\mathbf{- 6 . 7 9 7 9}$ \\
\hline
\end{tabular}

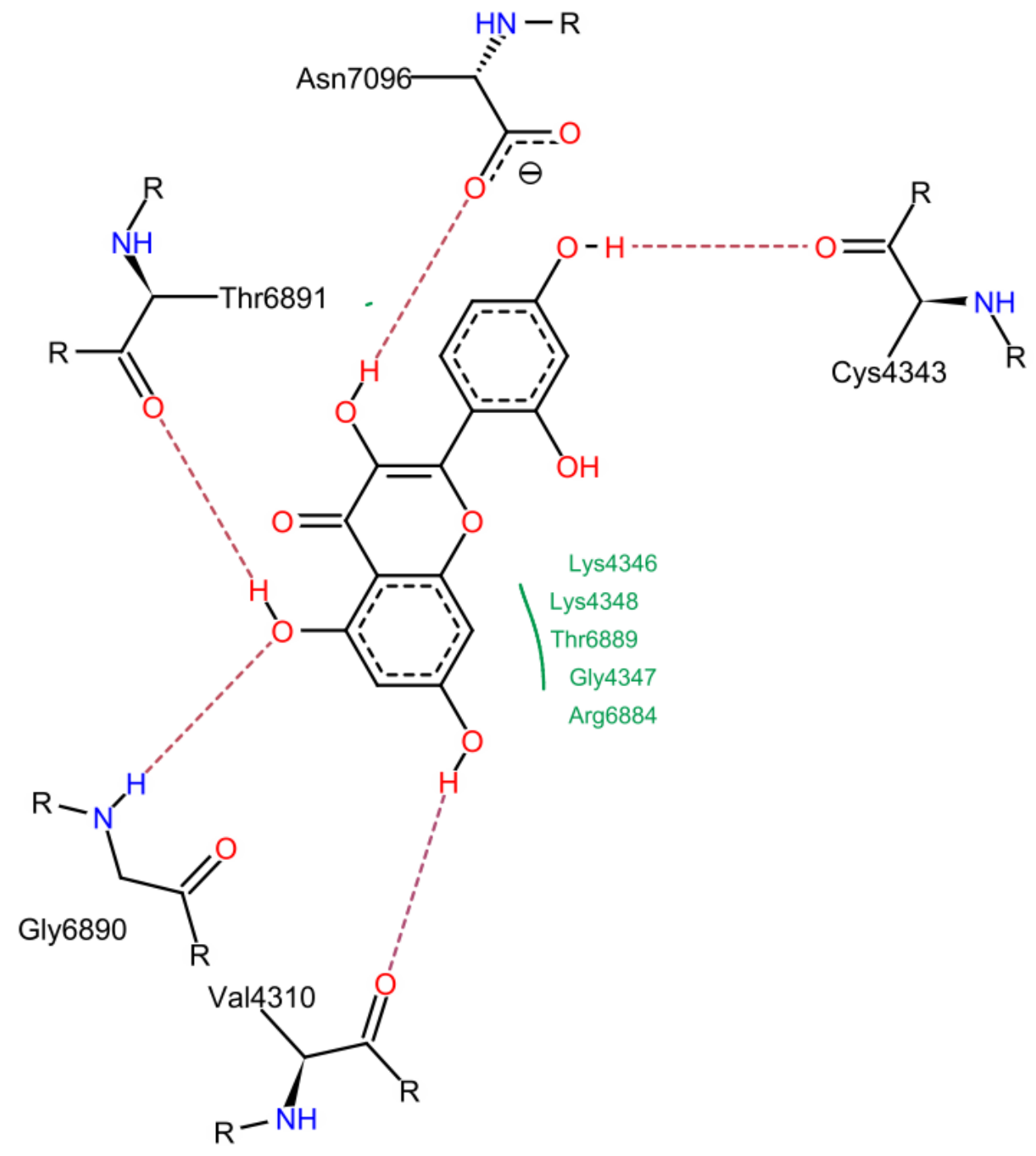

Figure 1: Binding pattern of Morin with NSP10 - NSP16 complex protein 


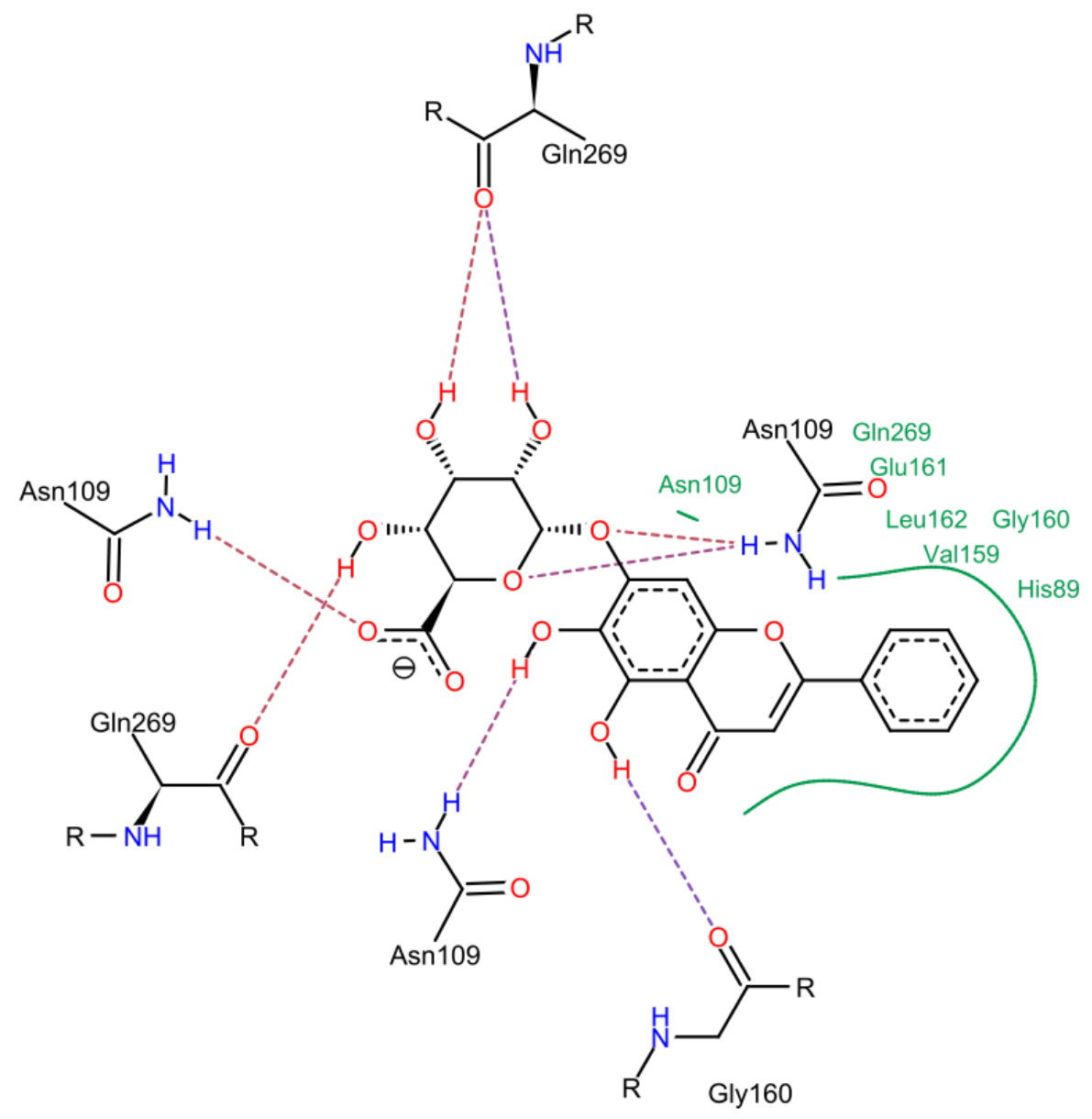

Figure 2: Binding pattern of Baicalin with papain-like protease

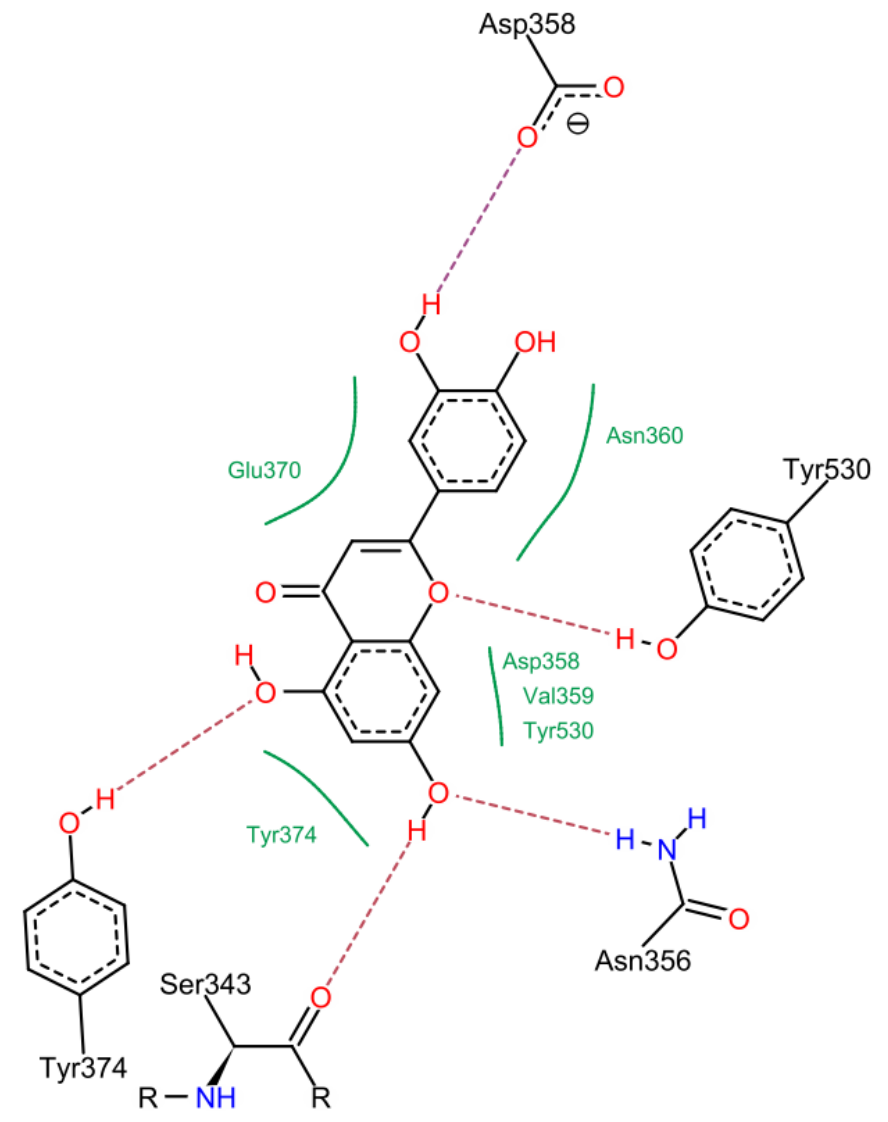

Figure 3: Binding pattern of Luteolin with RNA-dependent RNA polymerase 


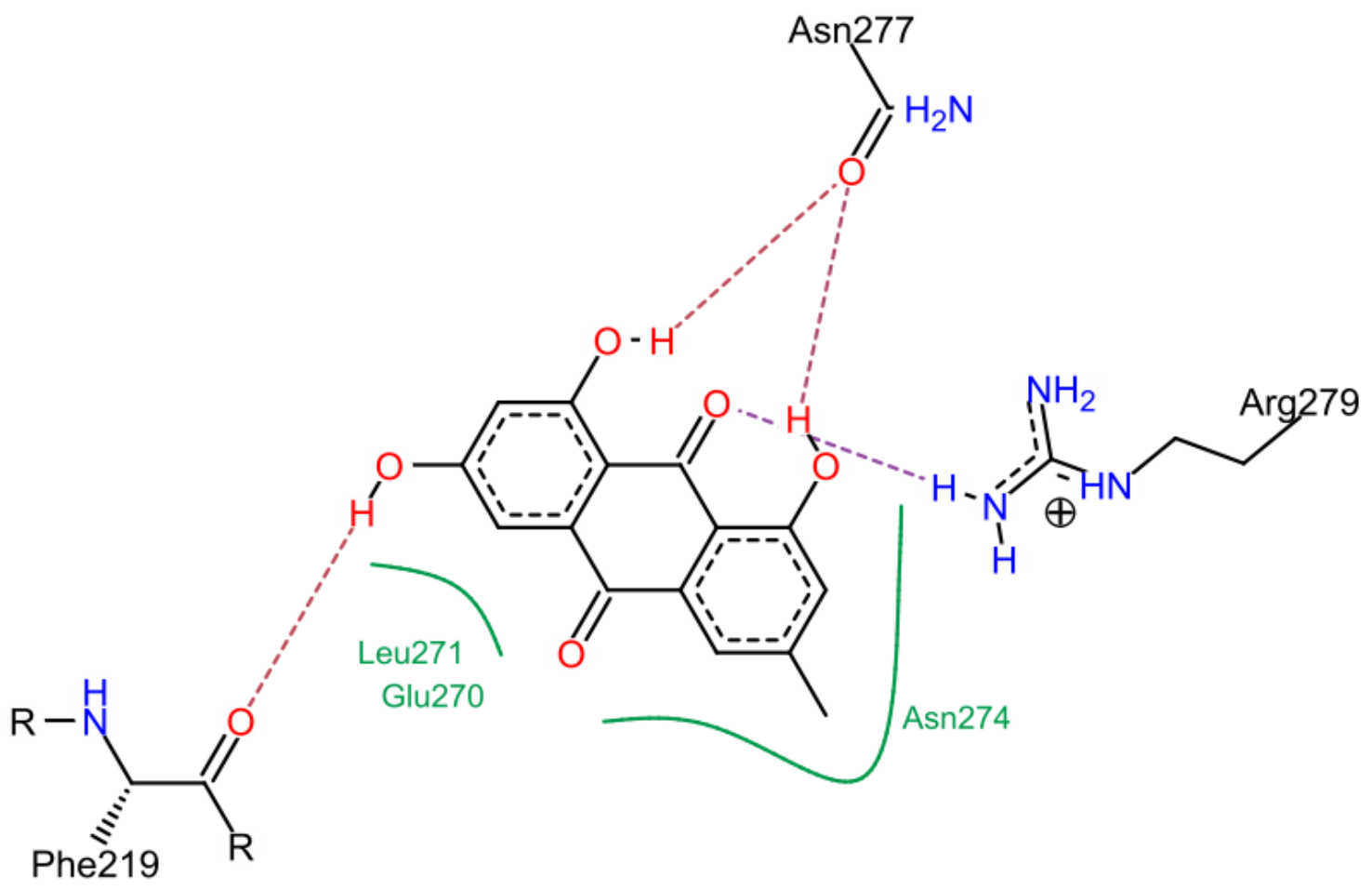

Figure 4: Binding pattern of Emodin with COVID-19 main protease 

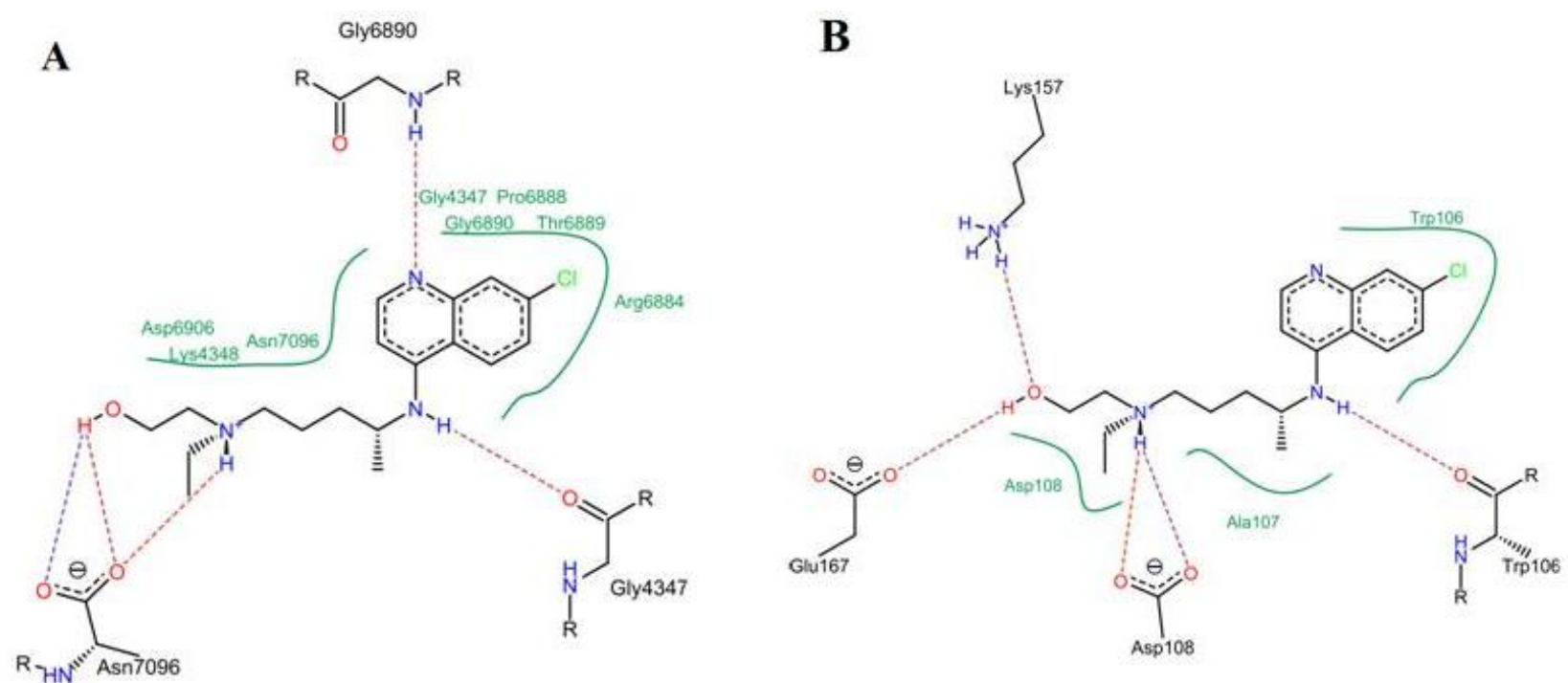

C

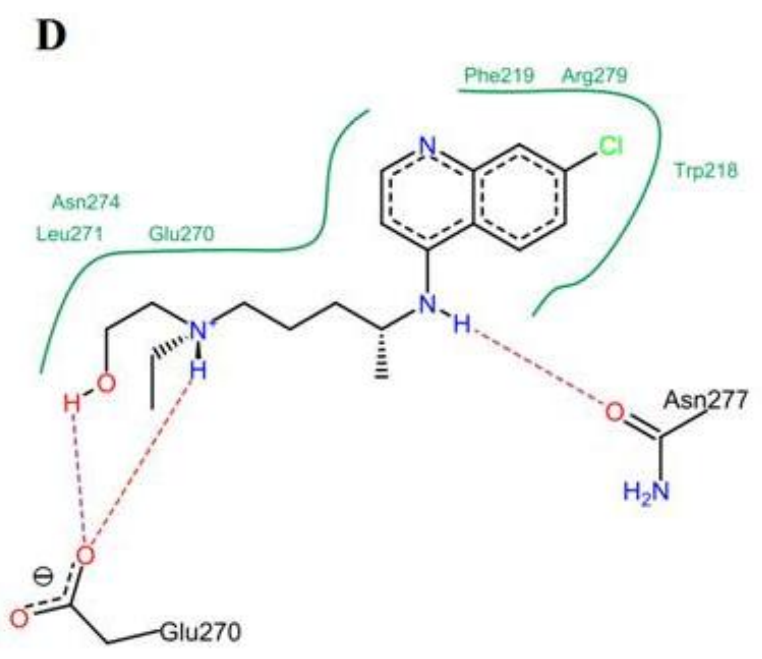

Figure 5: Binding pattern of Hydroxychloroquine with A: NSP10 - NSP16 Complex, B: papainlike protease, C: RNA-dependent RNA polymerase, D: main protease

\section{Discussions}

While considering better ligands, the least score in docking was preferred as it indicates more stability in binding ${ }^{24}$. The interactions of phytochemicals and control with targets were screened based on hydrogen bonding based prediction ${ }^{25}$. Docking score of Hydroxychloroquine (control), with NSP10 - NSP16 Complex, Papain-like protease, RNA-dependent RNA polymerase and COVID-19 main protease is $-16.8433 \mathrm{Kcal} / \mathrm{mol},-17.4223 \mathrm{Kcal} / \mathrm{mol},-15.7864$ $\mathrm{Kcal} / \mathrm{mol}$ and $-6.7979 \mathrm{Kcal} / \mathrm{mol}$ respectively and forms four hydrogen bonds with NSP10 NSP16 Complex, five hydrogen bonds with Papain-like protease, five hydrogen bonds with RNA-dependent RNA polymerase and forms three hydrogen bonds with COVID-19 main protease. 
Some phytochemicals exhibit better binding efficacy with NSP10 - NSP16 Complex protein, some shows strong bonding with Papain-like protease, some interact strongly with RNAdependent RNA polymerase and some others forms bond with COVID-19 main protease.

The flavone, morin isolated from Prunus dulcis, Chlorophora tinctoria, Psidium guajava and other plants shows better bonding with the target NSP10 - NSP16 Complex protein with a docking score of $-26.8255 \mathrm{Kcal} / \mathrm{mol}$ and forms five hydrogen bonds.

Baicalin a flavonoid obtained from roots of the plant Scutellaria baicalensis has the highest docking score $(-34.3309 \mathrm{Kcal} / \mathrm{mol})$ with the receptor papain-like protease among all the phytochemicals and control also forms seven hydrogen bonds with the receptor.

The flavone, luteolin isolated from Matricaria inodora L. plant has more binding efficacy with the target RNA-dependent RNA polymerase with a docking score of $-24.3635 \mathrm{Kcal} / \mathrm{mol}$ and forms five hydrogen bonds with the receptor.

Emodin a polyphenol found in the roots, leaves, and bark of several plants, including Aloe barbadensis, Rhamnus pushiana, Rheum officinale, Cassia angustifolia, Polygonum multiflorum, Polygonum cuspidatum, Psychotria camponutans etc. exhibit strong bonding with COVID-19 main protease receptor with docking score of $-20.0202 \mathrm{Kcal} / \mathrm{mol}$ and forms three hydrogen bonds.

From predicted ADME parameters and drug like nature of phytochemicals obtained from SwissADME web tool, it was found that some of the compounds do not obey the Lipinski's rule and show alert/warning in medicinal chemistry but being natural products these does not matter a lot.

Among the four best binding compounds with all targets, morin neither violate any rules nor shows any alert/ warning also it binds with all the targets significantly.

Hydroxychloroquine (control) forms hydrogen bonds with GLY4347, GLY6890 and ASN7096 residues of NSP10 - NSP16 Complex protein similarly morin forms hydrogen bonds with GLY6890, ASN7096, VAL4310, CYS4343 and THR6891 residues of the same receptor. Both form hydrogen bonds with GLY6890 and ASN7096 residues. Similar pattern was observed with other targets also.

The nsp10/nsp16 protein also known as RNA methyltransferase or MTase is a complex of two critical proteins bound together and the association makes the complex a functional protein. These proteins modify the genetic material of the virus to make it look more like the host (human) cell RNA and allow the virus to hide from the cells, giving it time to multiply. The nsp10/nsp16 protein is a key target because it is absolutely essential for the virus to replicate. If a drug can be developed to inhibit nsp10/nsp16, the immune system should be able to identify the 
virus and eliminate it earlier ${ }^{9}$, since morin interacts strongly with this target than other phytochemicals and control therefore it may inhibit nsp10/nsp16 protein and thus able to eradicate the virus.

Angiotensin converting enzyme 2 (ACE2) is the major cell receptor of SARS-CoV and SARSCoV-2. It plays a key role in the entrance of the virus into the cell to produce the final infection $^{26}$; interestingly morin has angiotensin converting enzyme inhibition activity also ${ }^{27}$.

Morin shows stable bonding pattern with all four targets in compare to other phytochemicals and control as it shows least score in docking, forms maximum number of hydrogen bonds with the active residues of the receptors, therefore morin have potentiality to be a drug candidate against Covid-19.

\section{Conclusion}

Based on present observation of docking results, ADME parameters and drug like nature, we suggest that morin may be a potent new drug candidate against Covid-19. However, further studies are required to validate the same in vivo or in vitro.

\section{Acknowledgements}

The authors are thankful to Department of Biotechnology (DBT), Govt. of India for establishing Bioinformatics Centre in Assam University, Silchar where the work has been carried out. The ejournal access facility (DeLCON) provided by Bioinformatics centre, Assam University funded by Department of Biotechnology, Govt. of India is highly acknowledged.

Conflict of Interest Statement: The authors declare no conflict of interests.

\section{References}

1. World Health Organization. SARS (Severe Acute Respiratory Syndrome). 2004. Available online: https://www.who.int/ith/diseases/sars/en/ (accessed on 22 April 2020).

2. Huang LL, Shen SP, Yu P, Wei YY. Dynamic basic reproduction number based evaluation for current prevention and control of COVID-19 outbreak in China. Zhonghua Liu Xing Bing Xue Za Zhi. 2020 Mar 1; 41(4):466-469.

3. Wang Y, Wang Y, Chen Y, Qin Q. Unique epidemiological and clinical features of the emerging 2019 novel coronavirus pneumonia (COVID-19) implicate special control measures. J Med Virol. 2020 Mar 5. doi: 10.1002/jmv.25748. [Epub ahead of print]

4. Zhu ZB, Zhong CK, Zhang KX, Dong C, Peng H, Xu T, Wang AL, Guo ZR, Zhang YH. Epidemic trend of corona virus disease 2019 (COVID-19) in mainland China. Zhonghua Yu Fang Yi Xue Za Zhi 2020 Mar 3; 54(0):E022.doi:10.3760/cma.j.cn112150-2020022200163. Online ahead of print. 
5. Rothan HA, Byrareddy SN. The epidemiology and pathogenesis of coronavirus disease (COVID-19) outbreak. J Autoimmun. 2020 May; 109:102433. doi: 10.1016/j.jaut.2020.102433. Epub 2020 Feb 26.

6. World Health Organization. Coronavirus Disease 2019 (COVID-19) Situation Report -43. 2020. Available online: https://www.who.int/emergencies/diseases/novel-coronavirus-2019 (accessed on 13 June 2020).

7. Xu J, Shi PY, Li H, Zhou J. Broad Spectrum Antiviral Agent Niclosamide and Its Therapeutic Potential. ACS Infect Dis. 2020 Mar 10. doi:10.1021/acsinfecdis.0c00052. [Epub ahead of print]. 8. Chen Y, Liu Q, Guo D. Emerging coronaviruses: Genome structure, replication, and pathogenesis. J Med Virol. 2020 Apr; 92(4):418-423.

9. New Drug Target Found for COVID-19 By Marla Paul on Mar 20, 2020. https://news.feinberg.northwestern.edu/2020/03/new-drug-target-found-for-covid-19/

10. COVID-19 and Drug Development - Towards Data Science. Source: https://towardsdatascience.com/covid-19-and-drug-development-b800d8917b50

11. Shinwari ZK. Medicinal plants research in Pakistan. J Med Plants Res. 2010 Feb 4; 4:161176.

12. De Smet PA. (2002) Herbal remedies. N Engl J Med. 2002 Dec 19; 347(25):2046-2056.

13. Gautret P, Lagier JC, Parola P, Hoang VT, Meddeb L, Mailhe M, Doudier B, Courjon J, Giordanengo V, Vieira VE, Dupont HT, Honoré S, Colson P, Chabrière E, La Scola B, Rolain JM, Brouqui P, Raoult D. Hydroxychloroquine and azithromycin as a treatment of COVID-19: results of an open-label non-randomized clinical trial. Int J Antimicrob Agents. 2020 Mar 20:105949. doi: 10.1016/j.ijantimicag.2020.105949. [Epub ahead of print]

14. Kapoor R, Sharma B, Kanwar SS. Antiviral Phytochemicals: An Overview. Biochem Physiol. 2017; 6: 220. doi: 10.4172/2168-9652.1000220

15. Perez RM. Antiviral Activity of Compounds Isolated From Plants. Pharmaceutical Biology. 2003; 41(2): 107-157.

16. Farnsworth NR, Svoboda GH, Blomster RN. Antiviral activity of selected Catharanthus alkaloids. J Pharm Sci. 1968; 57(12):2174-2175.

17. Ho TY, Wu SL, Chen JC, Li CC, Hsiang CY. Emodin blocks the SARS coronavirus spike Protein and angiotensin-converting enzyme 2 interaction. Antiviral Res. 2007; 74:92-101.

18. Naithani R, Huma LC, Holland LE, Shukla D, McCormick DL, Mehta RG, Moriarty RM. Antiviral activity of phytochemicals: a comprehensive review. Mini Rev Med Chem. 2008 Oct; 8(11):1106-33. 
19. Ben-Shabat S, Yarmolinsky L, Porat D, Dahan A. Antiviral effect of phytochemicals from medicinal plants: Applications and drug delivery strategies. Drug Deliv Transl Res. 2020; 10(2): 354-367.

20. Ul Qamar MT, Alqahtani SM, Alamri MA, Chen LL. Structural basis of SARS-CoV-2 $3 \mathrm{CL}^{\text {pro }}$ and anti-COVID-19 drug discovery from medicinal plants. J Pharm Anal. 2020 Mar 26. doi: 10.1016/j.jpha.2020.03.009. [Epub ahead of print].

21. O'Boyle NM, Banck M, James CA, Morley C, Vandermeersch T, Hutchison GR. Open Babel: an open chemical toolbox. J Chem Inf. 2011; 3:33.

22. Daina A, Michielin O, Zoete V. SwissADME: a free web tool to evaluate pharmacokinetics, drug-likeness and medicinal chemistry friendliness of small molecules. Sci Rep. 2017 Mar 3; $7: 42717$.

23. Simon S, Cross J. Improved FlexX Docking Using FlexS-Determined Base Fragment Placement. J. Chem. Inf. Model. 2005; 45(4): 993-1001.

24. Krovat EM, Steindl T, Langer T. Recent advances in docking and scoring. Curr Comp Aided Drug Design. 2005; 1: 93-102.

25. Bikadi Z, Demko L, Hazai E. Functional and structural characterization of a protein based on analysis of its hydrogen bonding network by hydrogen bonding plot. Arch Biochem Biophys. $2007 ; 461: 225-34$

26. Li W, Moore MJ, Vasilieva N, Sui J, Wong SK, Berne MA, Somasundaran M, Sullivan JL, Luzuriaga K, Greenough TC, Choe H, Farzan M. Angiotensin-converting enzyme 2 is a functional receptor for the SARS coronavirus. Nature. 2003 Nov 27; 426(6965):450-4.

27. Chen SY, Chu CC, Jiang CL, Duh PD. The Vasodilating Effect and Angiotensin Converting Enzyme Inhibition Activity of Three Dietary Flavonols: Comparsion between Myricetin, Quercetin and Morin, in vitro. J Food Nutr Res.2019; 7(5): 347-354. 